OPEN ACCESS

Edited by:

Barbara Metzler,

Topas Therapeutics GmbH, Germany

Reviewed by:

Willem Van Eden,

Utrecht University, Netherlands

Sylvaine You,

Institut National de la Santé et de la

Recherche Médicale (INSERM),

France

Eva M. Martinez-Caceres, Hospital Germans Trias i Pujol, Spain

*Correspondence:

Alf Hamann

hamann@drfz.de

${ }^{\dagger}$ Present address:

Mario Simonetti,

Molecular and Cellular Immunology/ Immune Regulation, Center for Regenerative Therapies Dresden,

Technische Universität Dresden, Dresden, Germany Bianca von Thülen,

Noack Laboratorien GmbH, Sarstedt, Germany

Specialty section:

This article was submitted to Immunological Tolerance and Regulation,

a section of the journal

Frontiers in Immunology

Received: 22 January 2020 Accepted: 22 September 2020

Published: 09 October 2020

Citation:

Pfeil J, Simonetti M, Lauer U, Volkmer $R$, von Thülen $B$, Durek $P$, Krähmer R, Leenders F. Hamann A and Hoffmann U (2020) Tolerogenic Immunomodulation by PEGylated Antigenic Peptides.

Front. Immunol. 11:529035. doi: 10.3389/fimmu.2020.529035

\section{Tolerogenic Immunomodulation by PEGylated Antigenic Peptides}

\author{
Jennifer Pfeil ${ }^{1,2}$, Mario Simonetti ${ }^{2 \dagger}$, Uta Lauer ${ }^{1,2}$, Rudolf Volkmer ${ }^{3}$, Bianca von Thülen ${ }^{4 \dagger}$, \\ Pawel Durek ${ }^{1}$, Ralf Krähmer ${ }^{4}$, Frank Leenders ${ }^{4}$, Alf Hamann ${ }^{1,2 *}$ and Ute Hoffmann ${ }^{1,2}$ \\ 1 Experimental Rheumatology, Deutsches Rheuma-Forschungszentrum, a Leibniz Institute (DRFZ), Berlin, Germany, \\ ${ }^{2}$ Department of Rheumatology and Clinical Immunology, Charité Universitätsmedizin, Berlin, Germany, ${ }^{3}$ Institute for Medical \\ Immunology, Charité Universitätsmedizin, Berlin, Germany, ${ }^{4}$ Celares GmbH, Berlin, Germany
}

Current treatments for autoimmune disorders rely on non-specific immunomodulatory and global immunosuppressive drugs, which show a variable degree of efficiency and are often accompanied by side effects. In contrast, strategies aiming at inducing antigenspecific tolerance promise an exclusive specificity of the immunomodulation. However, although successful in experimental models, peptide-based tolerogenic "inverse" vaccines have largely failed to show efficacy in clinical trials. Recent studies showed that repetitive $T$ cell epitopes, coupling of peptides to autologous cells, or peptides coupled to nanoparticles can improve the tolerogenic efficacy of peptides, suggesting that size and biophysical properties of antigen constructs affect the induction of tolerance. As these materials bear hurdles with respect to preparation or regulatory aspects, we wondered whether conjugation of peptides to the well-established and clinically proven synthetic material polyethylene glycol (PEG) might also work. We here coupled the T cell epitope OVA ${ }^{323-339}$ to polyethylene glycols of different size and structure and tested the impact of these nano-sized constructs on regulatory (Treg) and effector $T$ cells in the D011.10 adoptive transfer mouse model. Systemic vaccination with PEGylated peptides resulted in highly increased frequencies of Foxp3 ${ }^{+}$Tregs and reduced frequencies of antigen-specific $T$ cells producing pro-inflammatory TNF compared to vaccination with the native peptide. PEGylation was found to extend the bioavailability of the model peptide. Both tolerogenicity and bioavailability were dependent on PEG size and structure. In conclusion, PEGylation of antigenic peptides is an effective and feasible strategy to improve Treg-inducing, peptide-based vaccines with potential use for the treatment of autoimmune diseases, allergies, and transplant rejection.

Keywords: immune tolerance, autoimmunity, peptide vaccination, nanoparticles, regulatory $\mathrm{T}$ cells

\section{INTRODUCTION}

The limited efficacy and increased risk of opportunistic infection associated with classical immunosuppressants or modern biologics still represent a challenge in the therapy of immunemediated diseases such as autoimmunity, allergy, and transplant rejection. The resulting medical need has led to a revival of the old idea of antigen-specific therapies under the headline of "inverse vaccination" $(1,2)$. 
Numerous studies have demonstrated that the administration of soluble antigens or immunodominant peptides under noninflammatory conditions can indeed induce a state of unresponsiveness. Clonal deletion, induction of anergy, or modification in the cytokine profile of pro-inflammatory effector cells and, notably, induction and expansion of regulatory $\mathrm{T}$ cells (Tregs) were discussed as possible mechanisms in induced tolerance (3-8). Tregs play a pivotal role in maintaining selftolerance and in modulating immune responses in inflammatory diseases. Foxp $3^{+}$Tregs are generated either as a distinct lineage in the thymus during $\mathrm{T}$ cell development (tTregs) or in the periphery by conversion of conventional naive Foxp $3^{-} \mathrm{T}$ cells (pTregs) upon antigen exposure (9).

For use in tolerogenic vaccination, native protein antigens were first used and provide a broad spectrum of potential antigenic sites, while peptides representing immunodominant epitopes (as far as identified) are more "druggable" with regard to costs and regulatory issues. However, in part of animal studies and especially in first clinical trials in the human, peptide vaccination has not met the expectations. Both lack of efficacy and adverse effects, resulting in exacerbation of the autoimmune disease, were reported (10-13).

The efficacy of small peptides is restricted by their rapid excretion through the kidney or enzymatic degradation (14). This provoked further studies aiming to improve the tolerogenic potential of peptides by coupling to autologous cells $(15,16)$, to carrier proteins (17), coupling to or encapsulation of peptides into different kinds of nanoparticles (18-21), and others as reviewed in $(7,22-25)$.

In a preceding study, a tolerogenic effect of peptide epitopes was only observed when the peptide was multimerized or coupled to a repetitive carrier protein, but not as native peptide (17). This let us hypothesize that just molecular size is an important parameter in the tolerogenic efficacy. We previously reported that coupling of the OVA-peptide to dendritic oligoglycerol (OG)- or polyglycerol (PG)- nanoparticles resulted for some conjugates in an efficient induction of antigen-specific Tregs in vivo (20). In this study, linker chemistry, size, and structure were found to play a critical role for the tolerogenic potential of the conjugates.

Coupling of therapeutic proteins to another synthetic polymer, polyethylene glycol (PEG) is already widely applied for the optimization of biologics (26-28). PEG is a synthetic polymer composed of repetitive ethylene oxide subunits, either in linear form or as branched polymers. The covalent attachment of PEG (PEGylation) improves the pharmacokinetic and pharmacodynamic profile of biomolecules by increasing serum half-life. As PEG entangles around the peptide/protein surface and forms hydrogen bonds with the encircling water molecules, additional effects such as increased solubility of the conjugates, improved resistance to proteolysis, or reduced immunogenicity of biomolecules can be observed (29-32). We therefore analyzed here whether coupling of antigenic peptides to nano-sized PEG would improve efficacy and safety of vaccination. Numerous PEGylated biomolecules have already been approved by the Food Drug Administration (FDA) and the European Medicines Agency (EMA) for human use as ingredients of foods, cosmetics, and pharmaceuticals including topical, parenteral, and nasal formulations.

We therefore reasoned that coupling of peptides to PEG could provide not only favorable properties, notably increased size, and hence prolonged bioavailability but also safety and stability. Most important, coupling to PEG would build upon a clinically proven and well controllable chemistry. We used the transgenic DO11.10 adoptive transfer model (33) to test efficacy and safety of vaccination with PEG-coupled OVA-peptide. While in vitro, conjugates were much less efficient in activation of specific $\mathrm{T}$ cells than the native peptide, the contrary was true in vivo, correlating with an increased bioavailability of the conjugate. Systemic vaccination with PEGylated peptide resulted in highly increased frequencies of Foxp $3^{+}$Tregs as well as reduced frequencies of pro-inflammatory $\left(\mathrm{TNF}^{+}\right)$antigen-specific $\mathrm{T}$ cells, compared to vaccination with the native peptide. These data suggest that coupling of peptide to PEG might result in an improved tolerogenic activity.

\section{MATERIAL AND METHODS}

\section{Peptides}

OVA-peptide 323-339 (pOVA: ISQAVHAAHAEINEAGR), cysteine-modified pOVA (CG-ISQAVHAAHAEINEAGR) and cysteine-modified MOG-peptide 35-55 (CßA-MEVGWYRSPFS RVVHLYRNGK) were synthesized in house. N-terminally cysteine-modified peptides were used for conjugation to maleimido-functionalized PEG polymers.

\section{Preparation of PEGylated Peptides} (For formulas see Supplementary Figure 1).

\section{Synthesis of pOVA-PEG}

A 12-kDa PEG-maleimide was obtained from Quanta Biodesign (USA), 20 and $40 \mathrm{kDa}$ PEG-maleimide from NOF Corporation (Japan). To couple PEG to the CG-modified N-terminus of pOVA $_{323-339}, 450 \mathrm{mg}$ of $20 \mathrm{kDa}$ PEG-maleimide or $900 \mathrm{mg}$ of $40 \mathrm{kDa}$ PEG-maleimide and $40 \mathrm{mg}$ CG-pOVA $323-339$ were reacted in $40 \mathrm{~mL}$ of a $50 \mathrm{mmol} / \mathrm{L}$ of sodium phosphate buffer ( $\mathrm{pH}$ 7.0). The reaction mixture was stirred at RT for $1 \mathrm{~h}$. Progress of the reaction was monitored by RP-HPLC.

\section{Synthesis of pOVA-PEG-Tetramer}

To prepare a pOVA-PEG-tetramer, $54 \mathrm{mg}$ of CG-pOVA $323-339$ were reacted with $7 \mathrm{mg}$ of $4 \mathrm{arm}$-PEG-maleimide (celares $\mathrm{GmbH}$, Germany) in $4.5 \mathrm{ml}$ of $50 \mathrm{mmol} / \mathrm{L}$ of sodium phosphate buffer ( $\mathrm{pH}$ 7.2). The reaction mixture was stirred at RT for $2 \mathrm{~h}$. Progress of the reaction was monitored by RP-HPLC.

\section{Synthesis of pMOG-PEG20}

To couple PEG to the C-modified N-terminus of pMOG, $157 \mathrm{mg}$ of $20 \mathrm{kDa}$ PEG-maleimide (NOF Corporation, Japan) and $20 \mathrm{mg}$ pMOG were reacted in $20 \mathrm{~mL}$ of a $20 \mathrm{mmol} / \mathrm{L}$ of sodium phosphate buffer $\mathrm{pH} 7.2$ containing $250 \mu \mathrm{mol} / \mathrm{L}$ of Tris 
(2-carboxyethyl)phosphine. The reaction mixture was stirred at RT for $1 \mathrm{~h}$. Progress of the reaction was monitored by RP-HPLC.

\section{Purification of Peptide-PEG-Conjugates}

Crude peptide-PEG-conjugates were purified by cation-exchange chromatography using MacroCap SP on an Äkta chromatography system. pOVA-PEG-conjugates were bound to the resin in 20 $\mathrm{mmol} / \mathrm{L}$ of sodium citrate buffer $(\mathrm{pH} 3.0)$ as eluent and pMOGPEG20 in $20 \mathrm{mmol} / \mathrm{L}$ of sodium acetate $(\mathrm{pH} 4.5)$, respectively. Conjugates eluted with a linear sodium chloride gradient from 0 to $500 \mathrm{mM}$ in 10 column volumes in the same eluent. Conjugate elution was monitored at $213 \mathrm{~nm}$. Fractions containing the peptide-PEG-conjugates were pooled and desalted by dialysis against deionized water. Subsequently, conjugates were concentrated by freeze-drying. Prior to use, conjugates were reconstituted in WFI and filtered through a sterile $0.2 \mu \mathrm{m}$ filter.

\section{Analysis of Peptide-PEG-Conjugates}

Analysis of peptide-PEG-conjugates was performed by MALDIToF-MS, UV-spectrometry, and reversed phase-high performance liquid chromatography (RP-HPLC). RP-HPLC was performed on a Waters Alliance System. For the analysis of pOVA containing conjugates, an XBridge ${ }^{\mathrm{TM}} \mathrm{BEH} 300 \mathrm{C} 185 \mu \mathrm{m} 4.6$ x $250 \mathrm{~mm}$ was used. Samples were applied in water containing $0.1 \%$ TFA and eluted with a linear gradient from 37.5 to $50 \%$ acetonitrile in water each with $0.1 \%$ TFA in $15 \mathrm{~min}$. For the analysis of pMOG-PEG20, a Butyl C4 column 4.6 x $250 \mathrm{~mm}(5 \mu \mathrm{m})$ was used. Sample was eluted with a linear gradient from 70:15:15 to 50:25:25 water:acetonitrile: isopropanol each with $0.1 \%$ TFA in $10 \mathrm{~min}$. PEG or peptide-PEGconjugates were detected using an evaporating light scattering detector (ELSD). All peptide-PEG-conjugates were free of any residual unmodified peptide.

\section{Mice}

DO11.10 OVA-TCR ${ }^{+}$transgenic mice, extensively backcrossed ( $>10$ generations) onto BALB/c background, OTIIxB6.PL and $\mathrm{MHCII}^{-}{ }^{-}$ mice, extensively backcrossed (>10 generations) onto C57BL/6 background, were all housed in DRFZ breeding facility. Female $\mathrm{BALB} / \mathrm{c}$ mice were purchased from Charles River and used at 9 to 13 weeks of age. Mice were maintained under specific pathogen-free conditions according to national and institutional guidelines. All experiments were approved by Landesamt für Gesundheit und Soziales (LAGeSo).

\section{Cell Preparation}

To isolate OVA-TCR ${ }^{+} \mathrm{CD}^{+}$cells, single cell suspensions were prepared from peripheral lymph nodes (cervical, brachial, axillary and inguinal; pLN), mesenteric lymph nodes (mLN) and spleen isolated from DO11.10 or OTIIxB6PL mice. Red blood cells were lysed in lysis buffer (0.01 M potassium bicarbonate, $0.155 \mathrm{M}$ ammonium chloride, and $0.1 \mathrm{mM}$ ethylenediaminetetraacetic acid (EDTA) and washed with phosphate buffered saline (PBS) supplemented with $0.2 \%$ bovine serum albumin (BSA). $\mathrm{CD} 4^{+} \mathrm{T}$ cells from DO11.10 mice were enriched using anti-CD4 Microbeads (RM4-5, Miltenyi Biotec, Bergisch Gladbach, Germany) according to the manufacturer's instructions and sorted using an AutoMACS Pro (Miltenyi Biotec).
For preparation of OVA-TCR ${ }^{+} \mathrm{CD}^{+} \mathrm{MHCII}^{-}$cells from OTIIxBL6 mice anti-CD4-FITC and anti-MHCII-APC antibodies were added and incubated for $15 \mathrm{~min}$ at $4^{\circ} \mathrm{C}$. Subsequently, CD $4^{+}$ $\mathrm{MHCII}^{-}$cells were enriched using anti-FITC MultisortBeads (Miltenyi Biotec) and anti-APC Microbeads (Miltenyi Biotec) according to manufacturer's instructions. Purity of the CD4 ${ }^{+}$ $\mathrm{MHCII}^{-}$fraction was above $97 \%$, which was verified by flow cytometric analysis.

\section{Antibodies and Flow Cytometry}

The following antibodies were obtained from eBioscience (San Diego, CA, USA): eFluor 450-conjugated anti-CD4 (RM4-5), PeCy7-conjugated anti-CD11b (M1/70), PECy7-conjugated anti-IFN- $\gamma$ (XMG1.2), PerCP-eFluor 710-conjugated antiTNF $\alpha$ (MP6-XT22), eFluor 450-conjugated anti-Foxp3 (FJK$16 \mathrm{~s})$, and appropriate isotype controls. V500-conjugated anti-CD4 (RM4-5) antibody and PE-conjugated anti-Thy1.1 (OX-7) antibody were purchased from BD Bioscience (Heidelberg, Germany). PerCP-conjugated anti-CD11c (N418) and Pacific-Blue-conjugated anti-CD19 (6D5) antibodies were obtained from Biolegend (San Diego, USA). Cy5-conjugated anti-OVA-TCR (KJ1.26) and anti-Fc $\gamma$-receptor (2.4G2) antibodies were produced in house (DRFZ). Total rat IgG was purchased from Dianova (Hamburg, Germany). The APCconjugated anti-CD154 antibody was obtained from Miltenyi Biotec.

To stain surface molecules cells were incubated with anti-Fcyreceptor antibody $(20 \mu \mathrm{g} / \mathrm{ml})$. Cell fixation, permeabilization, and intracellular Foxp3 staining were performed using the eFluor450 anti-mouse Foxp3 (eBioscience) staining set according to manufacturer's instructions.

For cytokine staining, cells were stimulated in cRPMI supplemented with phorbol-12-myristate 13-acetate (PMA; 10 $\mathrm{ng} / \mathrm{ml})$ and ionomycin $(500 \mathrm{ng} / \mathrm{ml})$ for $4 \mathrm{~h}$ at $37^{\circ} \mathrm{C}$ in a humidified $5 \% \mathrm{CO}_{2}$ atmosphere. After $2 \mathrm{~h}$ incubation, Brefeldin A $(10 \mu \mathrm{g} / \mathrm{ml})$ was added. Cells were fixed by incubation with $2 \%$ paraformaldehyde (PFA) at RT. Intracellular staining was performed by $5 \mathrm{~min}$ pre-incubation with rat $\mathrm{IgG}$ in $0.5 \%$ saponin (all reagents from Sigma-Aldrich). Monoclonal rat antimouse cytokine antibodies were added and incubated for another $30 \mathrm{~min}$ in $0.5 \%$ saponin at RT. Flow cytometric analysis was performed using a FACS Canto II (BD Bioscience, Heidelberg, Germany) and Flow Jo software (Tree star, OR, USA).

\section{Determination of Cell Proliferation In Vitro and In Vivo}

For in vitro proliferation assays, $\mathrm{CD}^{+}$cells from DO11.10 mice were labeled with $1 \mu \mathrm{M}$ CFSE ( 5 ' carboxyfluorescein succinimidyl ester). The CD4 negative fraction was depleted from the remaining $\mathrm{T}$ cells using anti-CD90 Microbeads (Miltenyi Biotec) and AutoMACS separation according to the manufacturer's instructions and used as antigen-presenting cells (APCs). APCs were irradiated (30 Gray) and cultured with CFSE-labeled CD4 ${ }^{+}$ cells in a final concentration of $2 \times 10^{6}$ cells $/ \mathrm{ml}$ cRPMI (RPMI 1640 Glutamax medium, Gibco, supplemented with 10\% FCS, penicillin $100 \mathrm{U} / \mathrm{ml}$, streptomycin $100 \mu \mathrm{g} / \mathrm{ml}, 2$-mercaptoethanol $1 \mathrm{mM}$, sodium pyruvate $1 \mathrm{mM}$ and Hepes buffer $25 \mathrm{mM}$ ) 3:1 in 96-well 
round-bottom plates. Unconjugated pOVA or PEGylated peptides were added in concentrations as indicated. Cells were incubated for 4 days at $37^{\circ} \mathrm{C}$ in a humidified $5 \% \mathrm{CO}_{2}$ atmosphere.

For determination of cell proliferation, cells were analyzed by gating on $\mathrm{OVA}_{-} \mathrm{TCR}^{+} \mathrm{CD}^{+}$cells and calculating the geometrical mean of the fluorescence intensity (GMFI) of the CFSE signal. Fold CFSE dilution was determined as GMFI (PBS control)/ GMFI (sample) and plotted on a $\log _{2}$-scale where every log step represents one division step.

\section{Th1 Polarization}

$\mathrm{CD}^{+} \mathrm{T}$ cells were isolated from DO11.10 mice via MACSsorting as above and co-cultured 1:3 with APCs (CD4- CD90-) (final concentration: $2 \times 10^{6}$ cells $/ \mathrm{ml}$ ). Cells were incubated with $1 \mu \mathrm{g} / \mathrm{ml}$ of pOVA, IFN- $\gamma(20 \mathrm{ng} / \mathrm{ml}$ ) (R\&D Systems, McKinley, USA), IL12 (5 ng/ml) (R\&D), and anti-IL4-antibody (11B11, produced in house) $(5 \mu \mathrm{g} / \mathrm{ml})$. After 6 days, cells were harvested, and IFN- $\gamma$ expression was assessed via flow cytometry.

\section{Adoptive T Cell Transfer Assays Adoptive Transfer of Ex Vivo Isolated OVA-TCR ${ }^{+}$ CD4 ${ }^{+}$Cells}

On day $0,5 \times 10^{6}$ CFSE-labeled $\mathrm{CD}^{+}$cells from DO11.10 were adoptively transferred intravenously (i.v.) into syngeneic BALB/c mice. After 24 hours, mice were treated by a single i.v. injection of PBS (control), unconjugated pOVA or equimolar amounts of PEG-conjugated pOVA as indicated. In some experiments, mice were also treated with unconjugated pOVA $+50 \mu \mathrm{g}$ of lipopolysaccharide (LPS) or pOVA-PEG $+50 \mu \mathrm{g}$ of LPS. On day 7 , splenocytes were isolated, and OVA-TCR ${ }^{+} \mathrm{CD}^{+} \mathrm{T}$ cells were identified by an anti-KJ1.26 antibody, recognizing the OVA-specific TCR on transferred DO11.10 cells.

In experiments using $\mathrm{MHC}^{-} /^{-}$bone marrow (BM) chimeras, $5 \times 10^{6}$ CFSE-labeled OVA-TCR ${ }^{+} \mathrm{CD} 4 \mathrm{MHCII}^{-}$cells from OTIIxB6PL mice were adoptively transferred either into wt or $\mathrm{MHCII}^{-}$/ $\mathrm{BM}$ chimeras. 6 days after antigen exposure, splenocytes were isolated, and $\mathrm{OVA}_{-} \mathrm{TCR}^{+} \mathrm{CD}^{+} \mathrm{T}$ cells were identified by Th1.1 (CD90) on transferred OTIIxB6PL cells.

\section{Adoptive Transfer of Treg-Depleted CD4 ${ }^{+}$Cells}

To investigate whether Tregs are expanded or induced de novo, purified CFSE-labeled $\mathrm{CD}^{+} \mathrm{CD}^{-} 5^{-} \mathrm{CD} 103^{-} \mathrm{T}$ cells from DO11.10 mice were adoptively transferred i.v. into BALB/c mice. After $24 \mathrm{~h}$, mice were treated by a single i.v. injection of PBS (control), unconjugated pOVA at a dose of $5 \mu \mathrm{g}$ per mouse or equimolar amounts of PEGylated pOVA. On day 7, different lymphatic organs were isolated and OVA-specific $\mathrm{CD}^{+} \mathrm{T}$ cells were identified by an anti-KJ1.26 antibody.

\section{Adoptive Transfer of Antigen-Specific Th1 Cells}

$5 \times 10^{6}$ purified polarized CFSE-labeled Th1 cells from DO11.10 mice were adoptively transferred i.v. into BALB/c mice. After $24 \mathrm{~h}$, mice were treated by a single i.v. injection of PBS (control), unconjugated pOVA at a dose of $5 \mu \mathrm{g}$ per mouse or equimolar amounts of PEGylated pOVA. On day 5, splenocytes were isolated, and OVA-specific Th1 cells were identified by an anti-KJ1.26 antibody.

\section{Delayed-Type Hypersensitivity (DTH) Model}

pOVA-specific $\mathrm{CD}^{+}$cells were adoptively transferred into BALB/c mice, which were treated i.v. with PBS (control), $5 \mu \mathrm{g}$ of pOVA or equimolar amounts of pOVA-PEG20 $24 \mathrm{~h}$ later (tolerization). To induce the effector phase, in vitro generated pOVA-specific Th1 cells were transferred into the recipients on day 7. After $24 \mathrm{~h}$, pOVA in IFA or PBS/IFA were injected into the left or right hind footpad, respectively. Footpad swelling was monitored for 8 consecutive days and expressed as $\Delta$ footpad thickness.

\section{Analysis of Bioavailability}

To test for the presence of bioactive material in the organism after an extended period of time (bioavailability), recipients were treated with pOVA or equimolar amounts of PEGylated peptides 3 days before transfer of CFSE-labeled OVA-specific $\mathrm{CD} 4^{+}$cells. Proliferation was assessed 6 days after $\mathrm{CD}^{+}{ }^{+} \mathrm{T}$ cell transfer by dilution of CFSE intensity using flow cytometry.

\section{Generation of $\mathrm{MHCII}^{-} /{ }^{-}$Chimeric Mice}

Wt C57BL/6 recipient mice were lethally irradiated with 10.5 Gray. After $24 \mathrm{~h}$ mice were reconstituted by a single i.v. injection of $5 \times 10^{6} \mathrm{BM}$ cells from either $\mathrm{MHCII}^{-} /$mice or wt C57BL/6 BM cells (control). Therefore, $\mathrm{BM}$ cells from $\mathrm{MHCII}^{-} /$and $\mathrm{wt}$ C57BL/6 (control) were enriched by depletion of $\mathrm{CD}^{+} 0^{+}$cells using anti-CD90 Microbeads according to the manufacturer's instructions. Starting one week prior and ending 7 weeks after BM transplantation, BM chimeras continuously received $0.4 \%$ enrofloxacin (Baytril ${ }^{\circledR}$, Bayer, Leverkusen, Germany). After 7 weeks, reconstitution with $\mathrm{MHCII}^{-}$- $\mathrm{BM}$ cells was confirmed using flow cytometry (Supplementary Figure 6). Within the tissues radioresistant non-hematopoietic APCs remained $\mathrm{MHCII}^{+}$, whereas recipient hematopoietic APCs were replaced by $\mathrm{MHCII}^{-}{ }^{-}$donor cells (34).

\section{Statistics}

Data was analyzed using PRISM 5, 7 or 8 (GraphPad, La Jolla, CA, USA). Significance was determined with the non-parametric Mann Whitney U test followed by Holm-Bonferroni correction. Differences were considered as statistically significant with $\mathrm{p} \leq$ $0.05\left(^{*}\right)$, very significant with $\left.\mathrm{p} \leq 0.01{ }^{* *}\right)$, and extremely significant with $\left.\mathrm{p} \leq 0.001{ }^{* * *}\right)$ or marked as non-significant (ns). Data of in vitro dose response (Figure 1B) were additionally analyzed by curve fitting using global nonlinear fitting of the default Hill model, as described in detail in Supplementary Figure 2. For footpad swelling curves (Figure 11), significance was determined on all values using the Mann Whitney U test followed by Holm-Bonferroni correction.

\section{RESULTS}

\section{Biologic Activity of PEGylated Peptides}

In order to test whether $\mathrm{T}$ cell stimulation capacity is preserved after conjugation to different PEG carriers, the model peptide ovalbumin peptide 323-339 (pOVA) was either monovalently conjugated to linear PEG molecules [PEG20 (20 kDa) or PEG40 
A

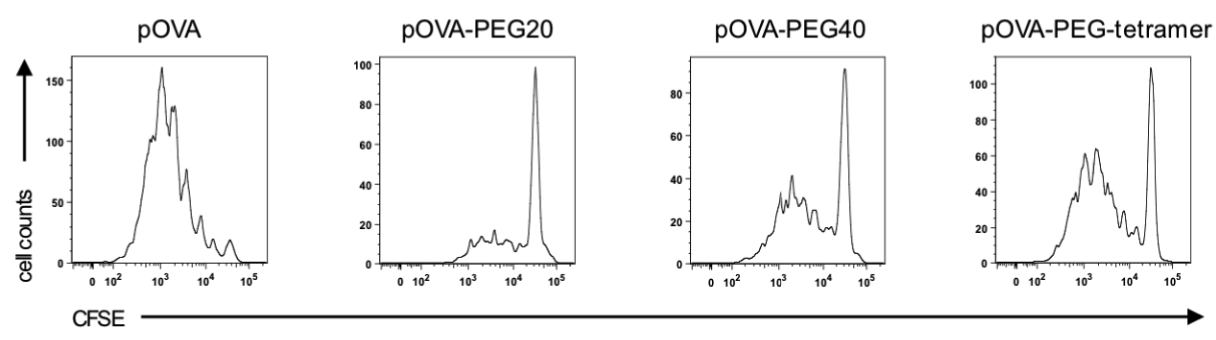

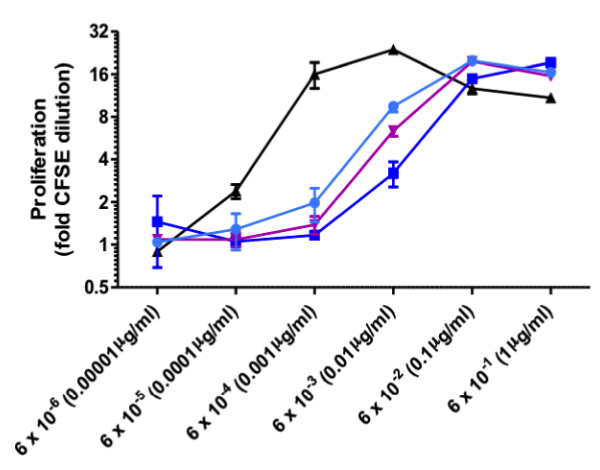

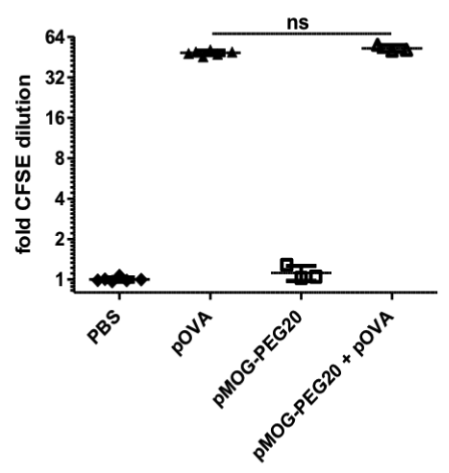

peptide concentration in $\mu \mathrm{M}(\mu \mathrm{g} / \mathrm{ml})$

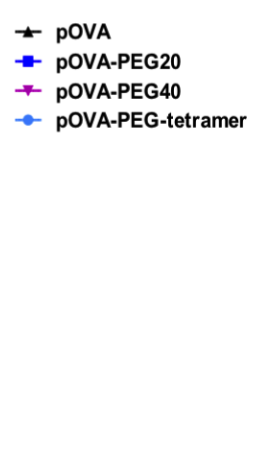

- pOVA-PEG20

- pOVA-PEG40

- pOVA-PEG-tetramer

DOVA-PEG-tetramer

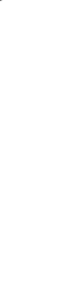


was used. OVA-specific CFSE-labeled $\mathrm{CD}^{+} \mathrm{T}$ cells from transgenic DO11.10 mice were transferred into syngeneic $\mathrm{BALB} / \mathrm{c}$ mice. After $24 \mathrm{~h}$, recipients were treated by a single i.v. injection of PBS (control), indicated amounts of pOVA or equimolar amounts (based on peptide amount) of pOVAPEG20, pOVA-PEG40 or pOVA-PEG-tetramer. After 6 days, splenocytes of recipients were isolated and OVA-specific $\mathrm{CD} 4^{+} \mathrm{T}$ cells were analyzed by flow cytometry. In contrast to the limited capacity of PEGylated peptides stimulating OVA-TCR ${ }^{+} \mathrm{CD}^{+} \mathrm{T}$ cells in vitro, $\mathrm{T}$ cells strongly proliferated when pOVA-PEG conjugates were administered in vivo (Figure 2). pOVA-PEG20 and especially pOVA-PEG40 and pOVA-PEG-tetramer were significantly more effective in activating OVA-specific cells than unconjugated pOVA.

\section{Conjugation of Peptide to PEG Prolongs Availability In Vivo}

We next addressed the question whether PEGylation leads to an extended half-life (bioavailability) of the antigenic peptide in the organism and whether size and structure of the PEG molecule matter. For this, we tested the degree of proliferation after vaccination with a single i.v. injection of pOVA or conjugates at 3 days prior to transfer of OVA-specific T cells (Figure 3A). Six days after cell transfer, splenocytes were isolated and proliferation of OVA-TCR ${ }^{+} \mathrm{CD}^{+} \mathrm{T}$ cells was analyzed according to CFSE content. Little $\mathrm{T}$ cell proliferation was observed upon vaccination with unconjugated pOVA or a 12 $\mathrm{kDa}$ PEG (pOVA-PEG12), suggesting a rapid systemic clearance within the three days (Figure 3B). In contrast, pOVA-PEG20, pOVA-PEG40 and pOVA-PEG-tetramer led to significant proliferation. Interestingly, pOVA-PEG-tetramer induced, despite its small size (4 x $1.9 \mathrm{kDa}$ pOVA + 3.1 kDa PEG; in total $11 \mathrm{kDa}$ ), proliferation as strong as pOVA-PEG40.

\section{Tolerogenic Potential of PEGylated Peptides In Vivo} Induction of Tregs

To assess the immunomodulatory effect of administration of different types of PEGylated pOVA, we analyzed the expression of Foxp3, the master transcription factor of Tregs and the cytokine profile of antigen-specific $\mathrm{T}$ cells upon vaccination. A significant increase in the frequency of splenic OVA-specific Foxp $3^{+}$regulatory T cells was observed following i.v. administration of $5 \mu \mathrm{g}$ of $(2.8 \mathrm{nM})$ native pOVA compared to PBS-treated mice (Figures $\mathbf{4 A - C}$ ). The effect was antigen-specific since the frequency of Foxp $3^{+}$Tregs was not altered among endogenous $\mathrm{CD} 4^{+} \mathrm{T}$ cells lacking the transgenic TCR (data not shown). Vaccination with equimolar amounts of pOVA-PEG20, pOVA-PEG40, and pOVA-PEG-tetramer also increased Foxp $3^{+}$frequencies among OVA-TCR ${ }^{+}$cells (Figures 4B, C) compared to PBS control, but only pOVA-PEG20 at a dose of $5 \mu \mathrm{g}$ (based on peptide amount) was significantly more efficient than unconjugated pOVA.

\section{Expansion of Pre-Existing Tregs or De Novo Induction?}

To investigate whether the increase of Treg frequency following pOVA-PEG20 treatment is due to de novo induction or to expansion of pre-existing Tregs, we transferred Treg-depleted OVA-specific $\mathrm{CD}^{+}{ }^{+} \mathrm{T}$ cells prior to vaccination with pOVA or pOVA-PEG20. Six days after tolerogenic vaccination, secondary lymphoid organs [spleen, $\mathrm{pLN}, \mathrm{mLN}$, and liver-draining lymph node (livLN)] were isolated and Foxp3 expression of OVA-TCR ${ }^{+} \mathrm{CD}^{+}{ }^{+} \mathrm{T}$ cells was assessed using flow cytometry. pOVA and pOVA-PEG20 were able to induce Foxp $3^{+}$Tregs in all organs analyzed (Figure 5). The frequency of Foxp $3^{+}$ Tregs reached similar levels following pOVA and pOVA-PEG20 administration in both spleen and pLN, whereas pOVA-PEG20

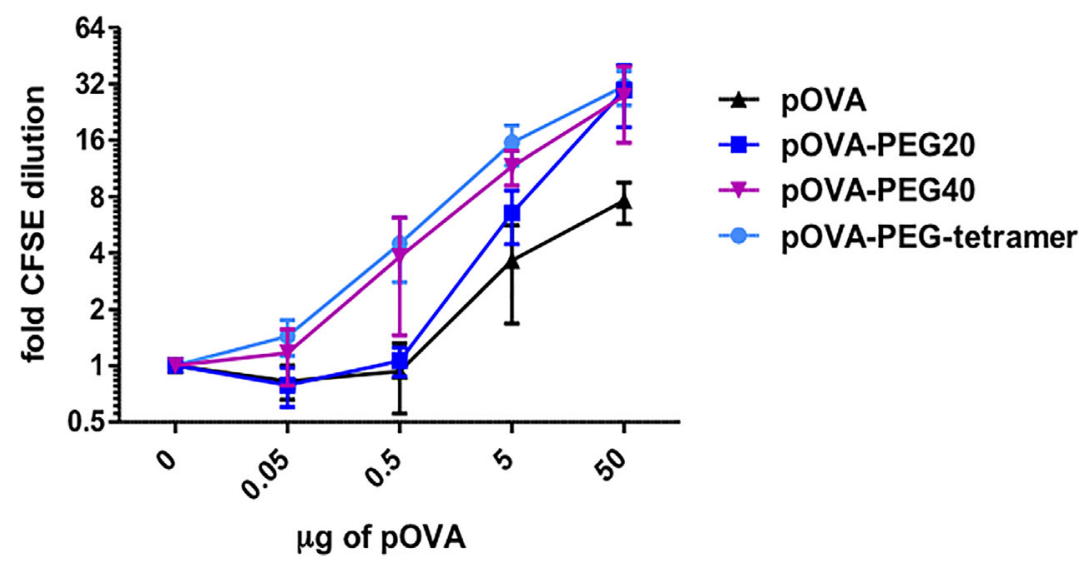

FIGURE 2 | PEGylated peptides efficiently activate antigen-specific CD4 ${ }^{+}$T cells in vivo. CFSE-labeled CD4 ${ }^{+}$T cells from DO11.10 mice were transferred into BALB/ c mice. After $24 \mathrm{~h}$ recipients received i.v. PBS (control), indicated amounts of pOVA or equimolar amounts (based on peptide amount) of pOVA-PEG20, pOVAPEG40 or pOVA-PEG-tetramer. $5 \mu \mathrm{g}$ of pOVA are equivalent to $2.8 \mathrm{nM}$ (and $250 \mu \mathrm{g} / \mathrm{kg}$ ) per mouse. After 6 days, proliferation was assessed by flow cytometry (for

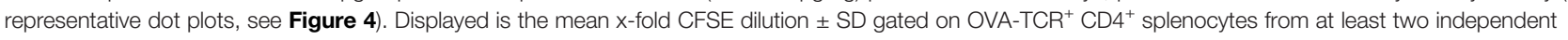
experiments. $n=4-6$; PBS, $n=10$. 

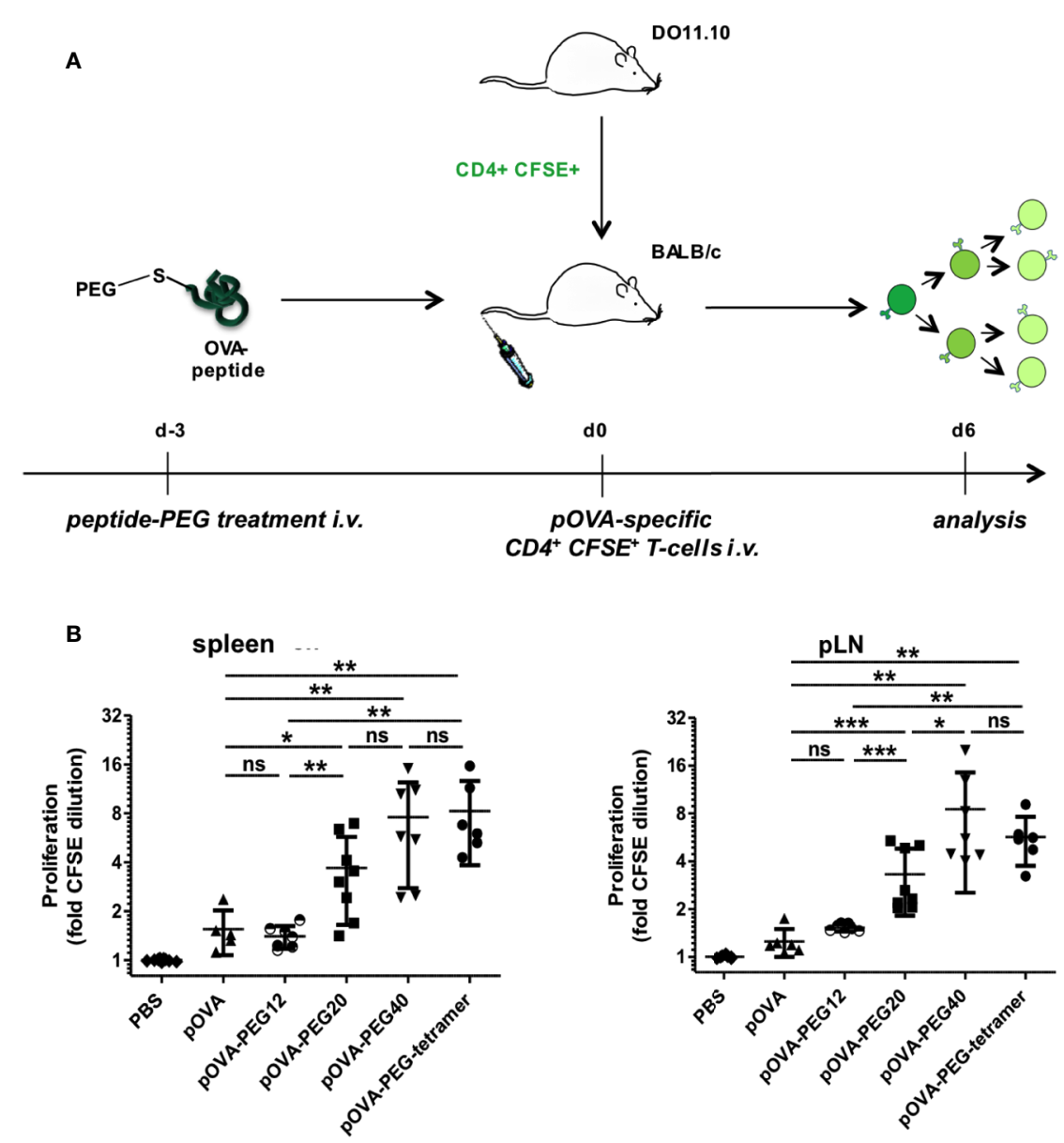

FIGURE 3 | Conjugation of pOVA to the macromolecular carrier PEG extends peptide bioavailability. (A) Set-up for analysis of the bioavailability. (B) OVA-specific CD4 ${ }^{+}$CFSE-labeled T cells were transferred into BALB/c mice three days after i.v. peptide vaccination with unconjugated pOVA or equimolar amounts of pOVA-PEG conjugates. After 6 days proliferation was assessed by flow cytometry. Cells from spleen and pLN were gated on OVA-TCR ${ }^{+} \mathrm{CD}^{+} \mathrm{T}$ cells. Data show mean $\mathrm{x}$-fold CFSE dilution \pm SD from at least two independent experiments. $n=6-9$. Statistical testing was performed using the nonparametric Mann Whitney test and HolmBonferroni correction for multiple comparisons. ns, non-significant; $\left(^{\star}\right) p<0.05 ;\left(^{\star \star}\right) p<0.01 ;\left(^{(\star \star}\right) p<0.001$.

increased the Treg frequency in mLN (trend) and the livLN (significant) compared to pOVA. Interestingly, the frequency of Foxp $3^{+}$cells was not as high as observed by adoptive transfer of $\mathrm{CD}^{+}$populations including Tregs (Figure 4), suggesting that administration of PEGylated pOVA leads to both de novo induction of Foxp $3^{+}$Tregs and to expansion of preexisting Tregs.

\section{Reduction of Pro-Inflammatory Effector Cells}

Another important mechanism of tolerance induction by systemic peptide encounter beside Treg induction is a diminished pro-inflammatory cytokine response, reflecting anergy of cells or depletion of the effector population.

At a dose of $5 \mu \mathrm{g}$, all PEGylated conjugates significantly reduced the frequency of TNF-producing cells among the OVA-specific T cells compared to PBS (Figures 6A-C). Interestingly, pOVA-PEG40 and pOVA-PEG-tetramer were superior in suppressing the TNF response already at lower doses. Under the conditions used (day 7), almost no IFN- $\gamma$ or IL-10 - positive cells could be detected (Supplementary Figure 3).

The combined impact of tolerogenic vaccination on both induction/expansion of Foxp $3^{+}$Tregs and reduction of TNFproducing cells was visualized by the ratio of TNF-producing to Foxp3 expressing cells, representing the effector/regulatory $\mathrm{T}$ cell ratio in vivo. The lowest effector cell/Treg ratio was found in animals treated with pOVA-PEG20 at a dose of $5 \mu \mathrm{g}$ (pOVAPEG20: mean ratio $=1.25$; pOVA-PEG40: 1.42 ; pOVA-PEGtetramer: 1.61; pOVA: 2.23; PBS: 10.79; Figure 7).

Besides Treg expansion/induction and anergy, deletion of antigen-specific $\mathrm{T}$ effector cells by activation-induced cell death also dampens the immune response. While unconjugated pOVA was not reducing the frequency of OVA-specific cells among host cells (reflecting their absolute number) until day 6, pOVA-PEG20 significantly reduced their frequency compared to both PBS and non-modified pOVA (Figure 8), despite inducing a slightly stronger 
A
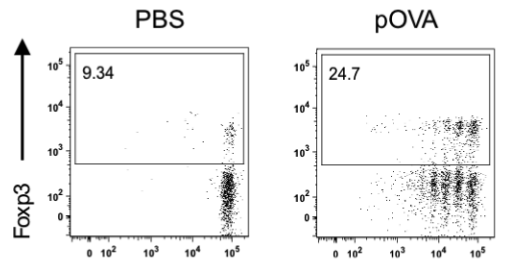

pOVA-PEG20

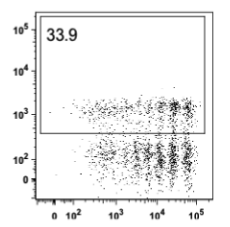

POVA-PEG40

pOVA-PEG-tetramer

CFSE

B

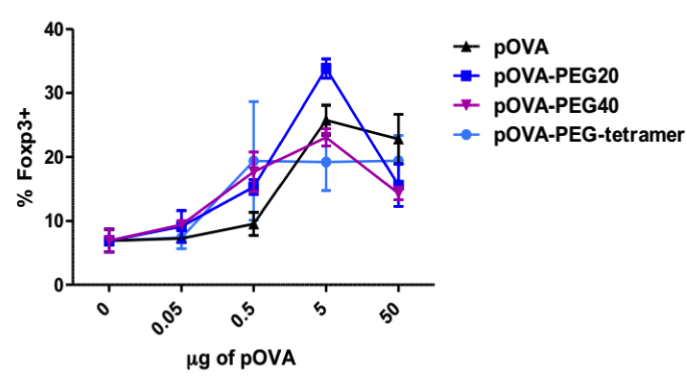

c

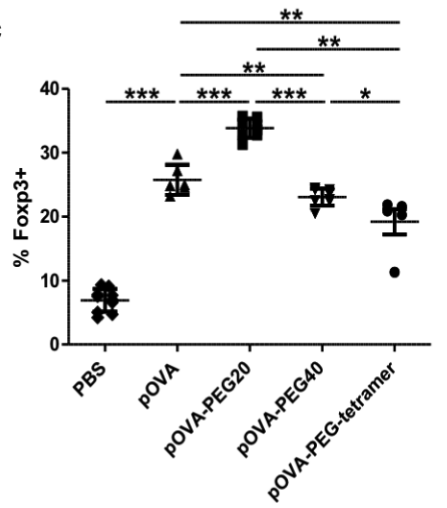

FIGURE 4 | Increased frequency of regulatory Foxp3 ${ }^{+} \mathrm{CD}^{+}$T cells upon pOVA-PEG20 treatment. CFSE-labeled CD4 ${ }^{+}$cells from DO11.10 mice were transferred into BALB/c mice. After $24 \mathrm{~h}$, mice received either PBS (control), indicated doses of pOVA or equimolar amounts of PEGylated peptides. After 6 days, Foxp3 expression was assessed using flow cytometry. Spleen cells were gated on OVA-TCR ${ }^{+} \mathrm{CD}^{+} \mathrm{T}$ cells. (A) Representative FACS dot plots of Foxp3 expression following tolerization with POVA or POVA-PEG conjugates at a dose of $5 \mu \mathrm{g}$ (based on peptide amount). (B) Dose response curve in vivo. Data displayed as mean \pm $\mathrm{SD}$ of $\%$ Foxp3 $^{+}$cells from at least two independent experiments. $n=4-8 ;$ PBS, $n=10$. (C) Pooled data from treatment with $5 \mu \mathrm{g}$ of pOVA or equimolar amounts of PEGylated pOVA. Mean \pm SD from at least two independent experiments. Statistical testing was performed using the nonparametric Mann Whitney test and HolmBonferroni correction for multiple comparisons. $\left(^{\star}\right) p<0.05 ;\left(^{\star \star}\right) p<0.01 ;\left(^{(\star \star}\right) p<0.001$.

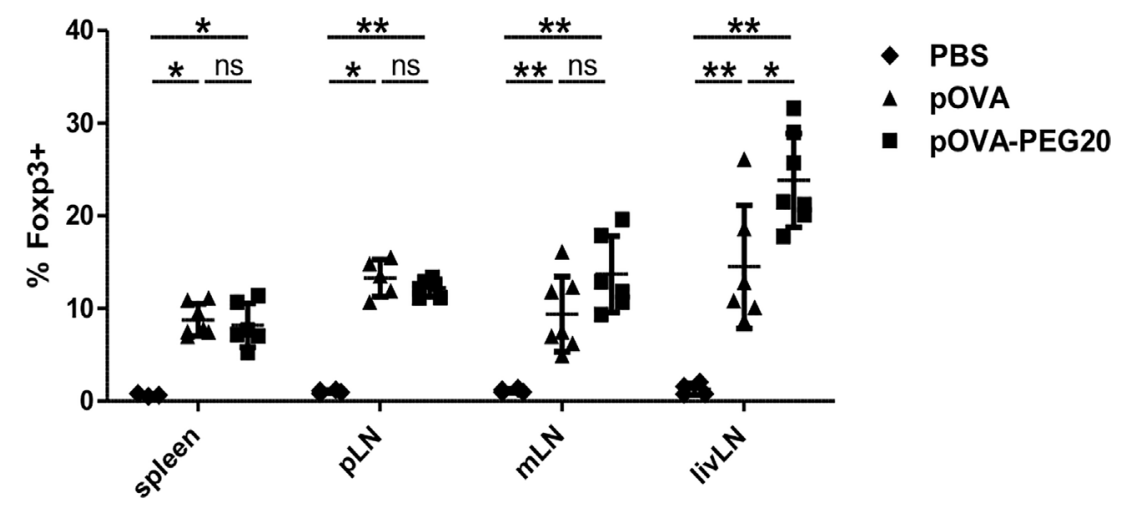

FIGURE 5 | Administration of pOVA-PEG20 leads to de novo induction of Foxp3 ${ }^{+}$Tregs. Treg-depleted CD4 ${ }^{+}$T cells from DO11.10 mice were transferred into BALB/c mice $24 \mathrm{~h}$ prior to treatment with PBS (control), $5 \mu \mathrm{g}$ of pOVA or equimolar amounts of pOVA-PEG2O. Six days post peptide vaccination, spleen, pLN, mLN and livLN were isolated and Foxp3 expression was analyzed using flow cytometry. Data were pooled from two experiments and represent mean \pm SD of $\%$ Foxp3 ${ }^{+}$ cells gated on OVA-TCR ${ }^{+} \mathrm{CD}^{+}$cells. $\mathrm{n}=3-7$. Statistical testing was performed using the nonparametric Mann Whitney test and Holm-Bonferroni correction for multiple comparisons. (ns) and all comparisons not marked were non-significant. ${ }^{*} p<0.05$; ${ }^{* \star} p<0.01$.

proliferation (Figure 2). Thus, vaccination with this conjugate is more efficient in triggering activation-induced death compared to native peptide or POVA-PEG-tetramer vaccination where some death might outbalance induced proliferation. Further analysis revealed that deletion of OVA-TCR ${ }^{+}$cells started to occur between day 3 and 4 post adoptive cell transfer (Supplementary Figure 4). In 
A

PBS

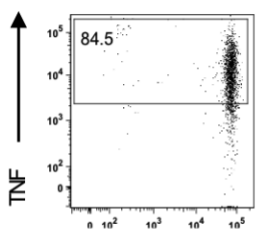

CFSE
pOVA

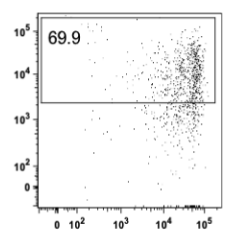

POVA-PEG20
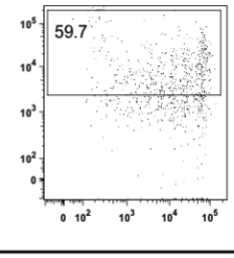

pOVA-PEG40

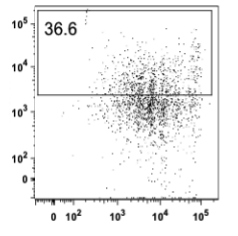

pOVA-PEG-tetramer

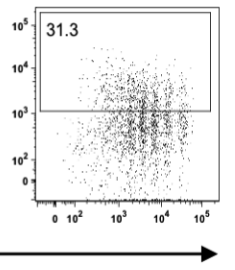

C
B

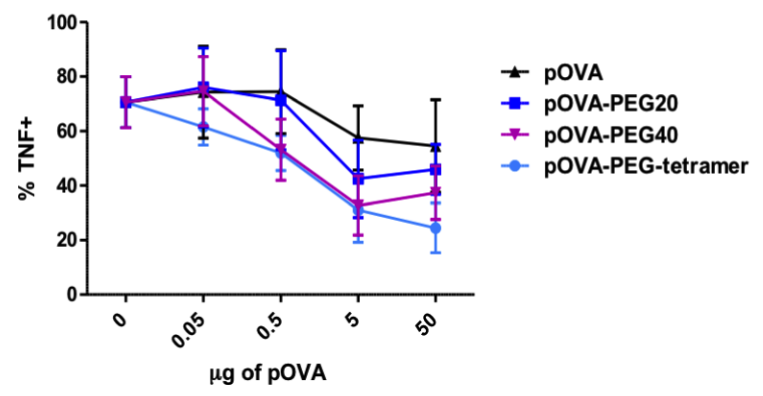

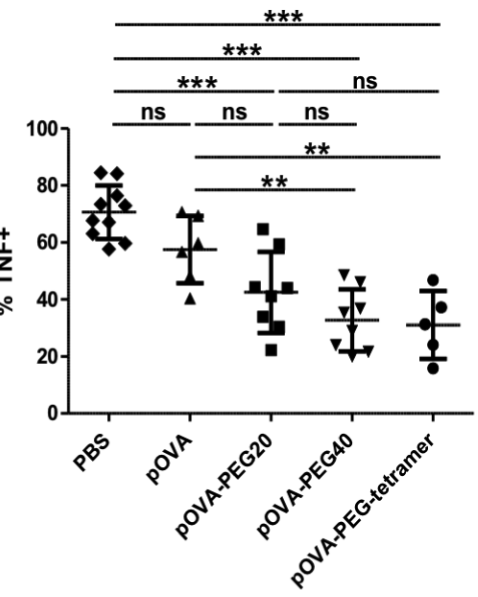

FIGURE 6 | Reduced frequency of TNF ${ }^{+}$among OVA-TCR ${ }^{+}$T cells upon treatment with PEGylated pOVA. $24 \mathrm{~h}$ after transfer of OVA-specific CFSE-labeled CD4 ${ }^{+} \mathrm{T}$ cells, recipients were treated i.v. with PBS (control), pOVA or equimolar amounts of pOVA-PEG conjugates. After 6 days, TNF production was assessed by intracellular staining of restimulated cells. Splenocytes were gated on OVA-TCR ${ }^{+} \mathrm{CD} 4^{+}$cells. (A) Representative FACS dot plots of TNF expression following tolerization with pOVA or pOVA-PEG conjugates at a dose of $5 \mu \mathrm{g}$ (based on peptide amount). (B) Dose response curve. Mean $\pm \mathrm{SD}$ of $\% \mathrm{TNF}^{+}$from at least two independent experiments. $n=4-6$; PBS, $n=10$. (C) Data for treatment with $5 \mu \mathrm{g}$ of pOVA or equimolar amounts of PEGylated pOVA. Mean \pm SD of $\%$ TNF ${ }^{+}$cells from at least two independent experiments. Statistical testing was performed using the nonparametric Mann Whitney test and Holm-Bonferroni correction for multiple comparisons. ns, non-significant, ${ }^{\star \star} p<0.01 ;{ }^{\star \star *} p<0.001$.

contrast to the other conjugates, administration of pOVA-PEG40 resulted in a net expansion of OVA-TCR ${ }^{+} \mathrm{CD}^{+}$cells.

In summary, conjugation of the PEG20 turned out to be the most effective modification with regard to increasing Foxp $3^{+}$Treg frequencies, decreasing pro-inflammatory TNF producing cells and depletion of antigen-reactive cells. Therefore, pOVA-PEG20 was chosen as the most promising candidate for tolerogenic vaccination approaches.

\section{Impact of pOVA-PEG20 on Pre-Existing Effector T Cells}

A potential field of application of tolerogenic vaccination is the treatment of autoimmunity or allergy. In these cases, effector cells are already present and might not only be resistant to conversion into Tregs but also bear the risk of exacerbating the disease by activation of the effector cells, as observed in peptide vaccination studies in experimental autoimmune encephalomyelitis (EAE) or allergy models $(10,11)$.

To analyze these questions, in vitro generated OVA-specific Th1 effector cells (Supplementary Figure 5) were transferred into $\mathrm{BALB} / \mathrm{c}$ mice prior to peptide vaccination. Proliferation and expression of IFN- $\gamma$ and Foxp3 were assessed on day 5. Although CFSE staining revealed a moderate proliferative response of the Th1 cells upon treatment of mice with pOVAPEG20 or pOVA (Figure 9A), again proliferation appeared to be outbalanced by induced cell death after pOVA-PEG20 treatment as both total OVA-specific and the fraction of IFN- $\gamma$-producing cells was not increased upon pOVA-PEG20 treatment (Figures 9B-E).

The low frequency of Foxp $3^{+}$cells among transferred cells was moderately increased upon administration of pOVA-PEG20 (Figures 9D, F).

To investigate the impact of inflammatory conditions, we analyzed the effect of lipopolysaccharide (LPS) application on the response of transferred unmanipulated OVA-TCR ${ }^{+} \mathrm{CD}^{+}$cells. While LPS did not further increase the frequency of TNFproducers, the expansion of $\mathrm{OVA}_{-} \mathrm{TCR}^{+} \mathrm{T}$ cells upon vaccination with pOVA-PEG20 was stronger in presence of LPS (Figures 10A, B). Remarkably, the increase in Foxp $3^{+}$ cells upon vaccination with pOVA or pOVA-PEG20 was completely suppressed in presence of LPS (Figure 10C). 


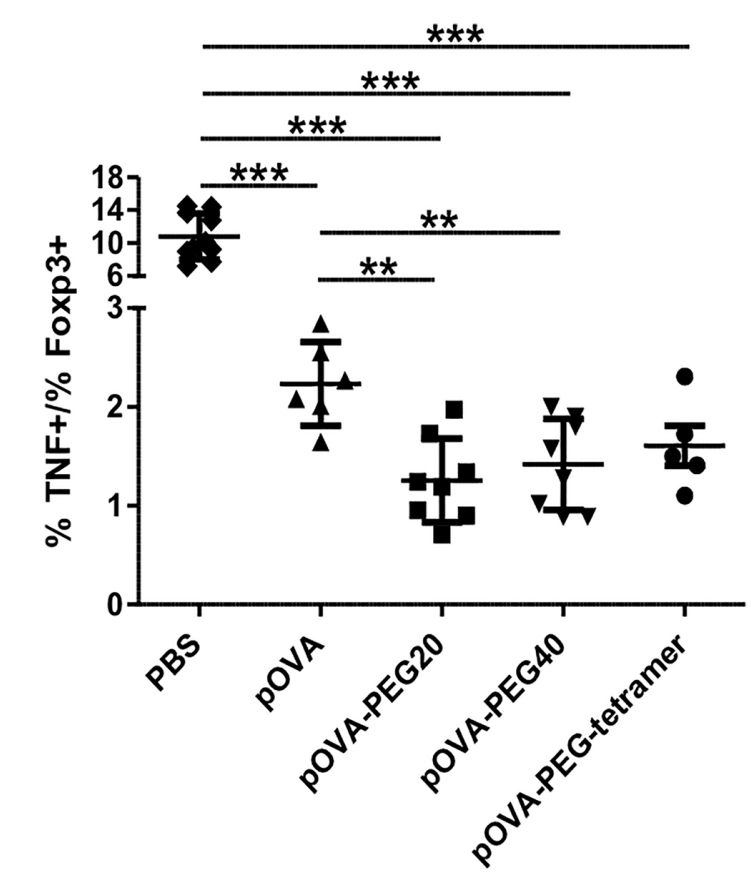

FIGURE 7 | Reduced TNF/Foxp3 ratio upon treatment with pOVA-PEG conjugates. $24 \mathrm{~h}$ after transfer of OVA-TCR ${ }^{+}$CFSE-labeled $\mathrm{CD}^{+} \mathrm{T}$ cells, recipients received PBS (control), $5 \mathrm{\mu g}$ of pOVA or equimolar amounts of different pOVA-PEG conjugates. After 6 days, TNF production and Foxp3 expression were assessed using flow cytometry for spleen cells. The TNF/Foxp3 ratio gated on OVA-TCR ${ }^{+} \mathrm{CD}_{4}{ }^{+}$cells was calculated, reflecting the effector T cell/ Treg ratio of responding cells. Mean $\pm \mathrm{SD}$ of the ratio $\% \mathrm{TNF}^{+} / \%$ Foxp3 ${ }^{+}$cells from at least two independent experiments; $n=5-8 ;$ PBS, $n=10$. Statistical testing was performed using the nonparametric Mann Whitney test and HolmBonferroni correction for multiple comparisons. ${ }^{* \star} p<0.01 ;{ }^{\star \star} p<0.001$.

\section{Tolerogenic Effects in a D011.10 Transfer-Based DTH Model}

To investigate whether pOVA-PEG20 is able to prevent the development of an inflammatory reaction in vivo, we used a DTH model based on the transfer of pre-formed Th1 cells, intrafootpad challenge with pOVA and measurement of footpad swelling for 8 days. As shown in Figure 11, only a slightly more efficient suppression by pOVA-PEG 20 compared to pOVA is observed (Mann Whitney $U$ test, adjusted $\mathrm{p}=0.03$ ) in this setting. As discussed below, a clearer superiority of PEGylated peptide over native peptide in tolerance induction was found in a more physiological EAE-model studied in parallel (35).

\section{Antigen Uptake and Presentation by Antigen-Presenting Cells}

The type and status of APC that present antigen in a given context can play a role in the induction of tolerance $(36,37)$. To investigate which APC population is able to take up pOVA-PEG20, pOVAPEG20 was conjugated to the fluorochrome fluorescein isothiocyanate (FITC) and the FITC $^{+}$fractions of major

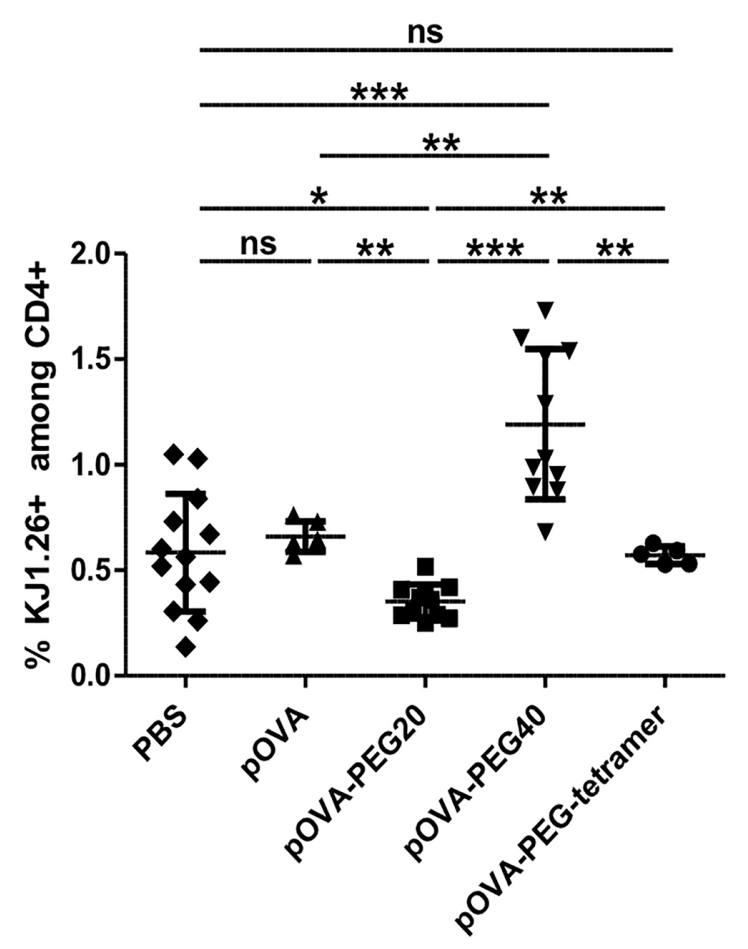

FIGURE 8 | Administration of pOVA-PEG20 reduces the frequency of OVA$\mathrm{TCR}^{+} \mathrm{CD}^{+} \mathrm{T}$ cells among total $\mathrm{CD} 4^{+}$splenocytes. OVA-specific $\mathrm{CD} 4^{+}$cells were transferred into BALB/c mice. After $24 \mathrm{~h}$, mice received i.v. PBS (control), $5 \mu \mathrm{g}$ of pOVA or equimolar amounts of POVA-PEG conjugates. After 6 days, the frequency of OVA-TCR ${ }^{+} \mathrm{CD}^{+}$cells among total $\mathrm{CD}^{+}{ }^{+} \mathrm{T}$ cells was assessed using flow cytometry. Mean $\pm \mathrm{SD}$ of $\% \mathrm{KJ} 1.26^{+}$cells $\left(\mathrm{OVA}-\mathrm{TCR}^{+} \mathrm{T}\right.$ cells) among total $\mathrm{CD}^{+}$splenocytes from at least two independent experiments. $n=5-11$; PBS, $n=13$. Statistical testing was performed using the nonparametric Mann Whitney test and Holm-Bonferroni correction for multiple comparisons. ns, non-significant, ${ }^{\star} \mathrm{p}<0.05 ;{ }^{* \star} \mathrm{p}<0.01$; ${ }^{* \star *} \mathrm{p}<0.001$.

subgroups of APC were identified by flow cytometry. Uptake of pOVA-PEG-FITC was observed by $C D 11 c^{+}$cells (DC) and

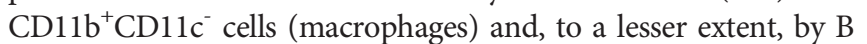
cells in all analyzed secondary lymphoid organs (Supplementary Figures 7,8 ), in partial agreement with previous studies of antigen presentation upon oral administration (38).

Besides APCs from hematopoietic origin, also nonhematopoietic cells are able to present antigens to $\mathrm{T}$ cells via the major histocompatibility complex class II (MHCII) (34, 3941). Especially liver sinusoidal endothelial cells have been associated with tolerogenic responses $(34,42)$. To investigate their role in presentation of pOVA-PEG20, chimeric mice devoid of hematopoietic $\mathrm{MHCII}^{+} \mathrm{APC}$ were used. Chimeric mice were generated by irradiation of wt C57BL/6 mice and reconstitution of the hematopoietic compartment with $\mathrm{BM}$ cells from $\mathrm{MHCII}^{-} /$ mice. After successful reconstitution, CFSE-labeled OVAspecific $\mathrm{MHCII}^{+}$depleted $\mathrm{CD}_{4}^{+}$cells isolated from transgenic OTIIxB6.PL mice were transferred into the BM chimeras 24 hours prior to pOVA-PEG20 administration. After 6 days, OVAspecific $\mathrm{CD} 4^{+}$splenocytes were isolated, and proliferation and Foxp3 expression were assessed by flow cytometry. 
A

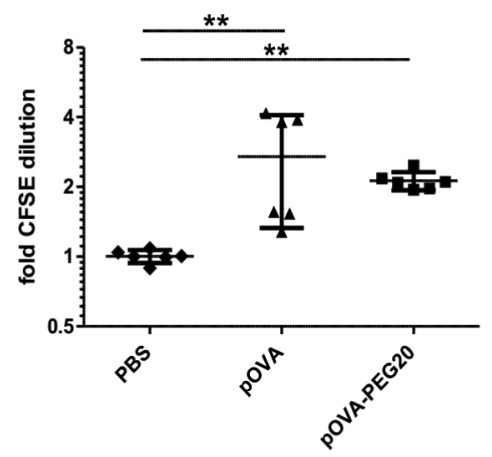

C

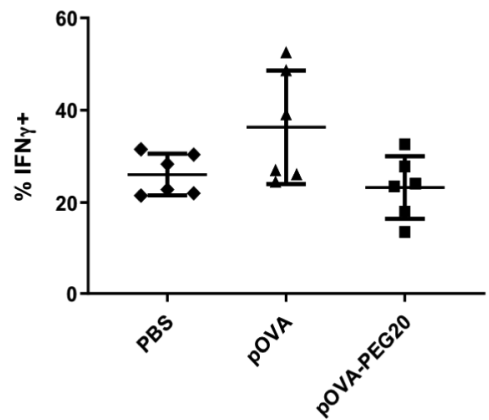

$\mathbf{E}$

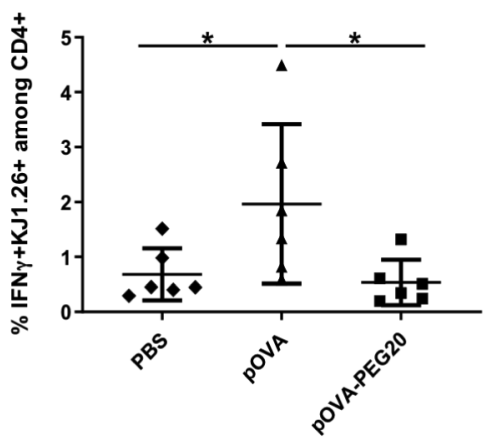

B

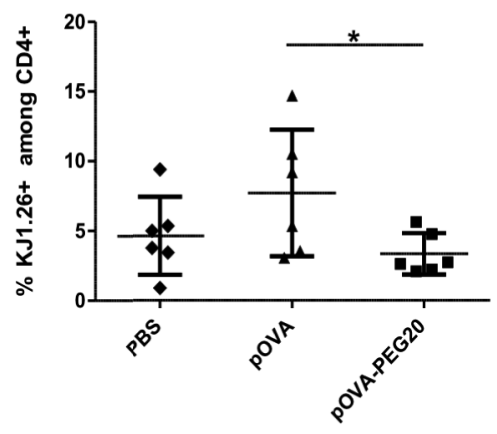

D

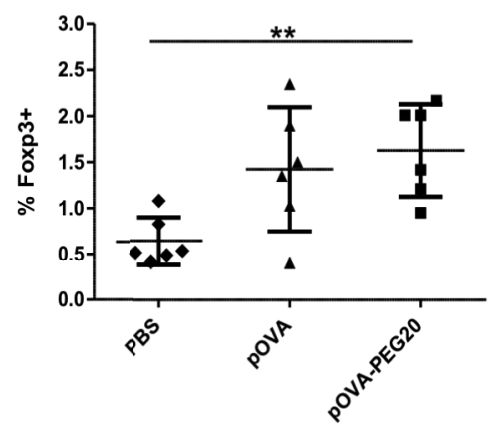

$\mathbf{F}$

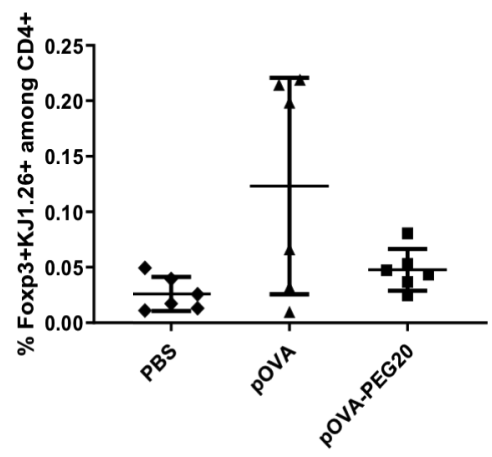

FIGURE 9 | pOVA-PEG20 vaccination in presence of pre-existing T effector cells. In vitro generated OVA-specific Th1 cells were labeled with CFSE and transferred into BALB/c mice. After $24 \mathrm{~h}$, recipients received i.v. PBS (control), $5 \mathrm{\mu g}$ of pOVA or equimolar amounts of pOVA-PEG20. After four days, splenocytes were reisolated and proliferation, IFN- $\gamma$ and TNF production as well as Foxp3 expression was assessed using flow cytometry. (A) Proliferation (X-fold CFSE dilution). (B) OVA-TCR ${ }^{+}$T cells among total CD4 ${ }^{+}$cells. (C) \% IFN- $\gamma$ producers among OVA-specific CD4 $4^{+}$cells. (D) \% Foxp3 ${ }^{+}$cells among OVA-specific CD4 ${ }^{+}$cells. (E, F) Absolute number of antigen-specific IFNy or Foxp3 ${ }^{+}$cells expressed as $\%$ of total $C D 4^{+}$. (A-F) Pooled data with mean \pm SD from two independent experiments; $n=$ 6. Non-marked comparisons are non-significant. Statistical testing was performed using the nonparametric Mann Whitney test and Holm-Bonferroni correction for multiple comparisons. $\left({ }^{*}\right) p<0.05 ;\left(^{\star *}\right) p<0.01$.

$5 \mu \mathrm{g}$ of pOVA-PEG20 (based on peptide amount) were sufficient to induce proliferation of $\mathrm{OVA}_{-} \mathrm{TCR}^{+} \mathrm{T}$ cells in $\mathrm{MHCII}^{+} /^{+}$(wt) control BM chimeras, whereas the equal dose did not activate OVA-specific cells in $\mathrm{MHCII}^{-} / \mathrm{BM}$ chimeras (Figure 12). Here, a tenfold dose $(50 \mu \mathrm{g})$ was required to induce $\mathrm{T}$ cell activation. In contrast to wt BM chimeras, Foxp3 Treg expansion was not observed in $\mathrm{MHCI}^{-} /^{-} \mathrm{BM}$ chimeras, neither at 5 nor at $50 \mu \mathrm{g}$, indicating that non-hematopoietic APCs are able to present pOVA-PEG20 and thereby activate OVA-specific $\mathrm{T}$ cells, but do not mediate induction or expansion of Foxp $3^{+}$Tregs.

\section{DISCUSSION}

Induction of tolerance by antigenic peptides has been notoriously inefficient and, in some cases, even aggravating disease. We here studied whether conjugation of antigenic peptides to a polyethylene glycol moiety can improve their tolerogenic potential by prolonging half-life and by reducing effector cell stimulation.

Coupling of peptide to PEG might prevent their presentation by MHC. DO11.10 T cells recognize a core epitope (329-339) with the primary and secondary TCR contact residues 333 and 331, respectively (43). N-terminal PEGylation of the OVA- 

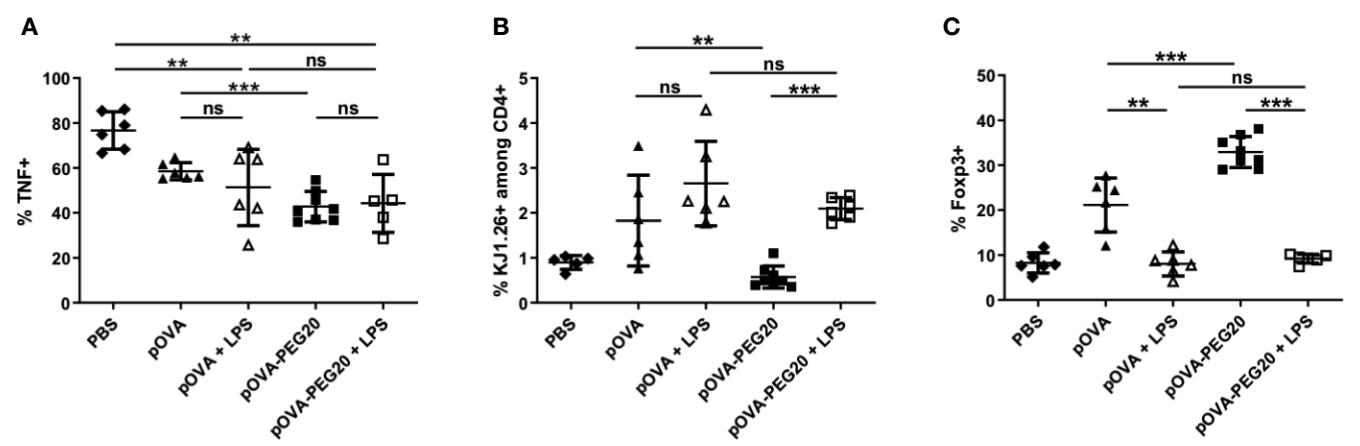

FIGURE 10 | Administration of $50 \mu \mathrm{g}$ of LPS does not enhance secretion of pro-inflammatory cytokines but inhibits induction/expansion of Foxp3 ${ }^{+}$Tregs upon treatment with pOVA-PEG20. $24 \mathrm{~h}$ after adoptive transfer of OVA-specific CD4 ${ }^{+} \mathrm{T}$ cells, recipients received i.v. PBS (control), $5 \mu \mathrm{g}$ of pOVA or equimolar amounts of pOVA-PEG conjugates with or without additional LPS. After 6 days, splenocytes were isolated and Foxp3 expression as well as TNF production was assessed by flow cytometry. (A) \% TNF ${ }^{+}$cells gated on OVA-specific CD4 $4^{+}$cells, mean $\pm \mathrm{SD}$ of data from three independent experiments. (B) \% KJ1.26 ${ }^{+}$(OVA-specific) splenocytes among total $\mathrm{CD}^{+}$population; mean $\pm \mathrm{SD}$ of pooled data from three independent experiments. (C) \% Foxp3 ${ }^{+}$cells gated on OVA-specific $\mathrm{CD} 4^{+}$cells; mean \pm SD of pooled data from three independent experiments. $n=5-6$; pOVA-PEG20, $n=8$. Statistical testing was performed using the nonparametric Mann Whitney test and Holm-Bonferroni correction for multiple comparisons. ns, non-significant, ${ }^{* *} p<0.01 ;{ }^{* \star *} p<0.001$.

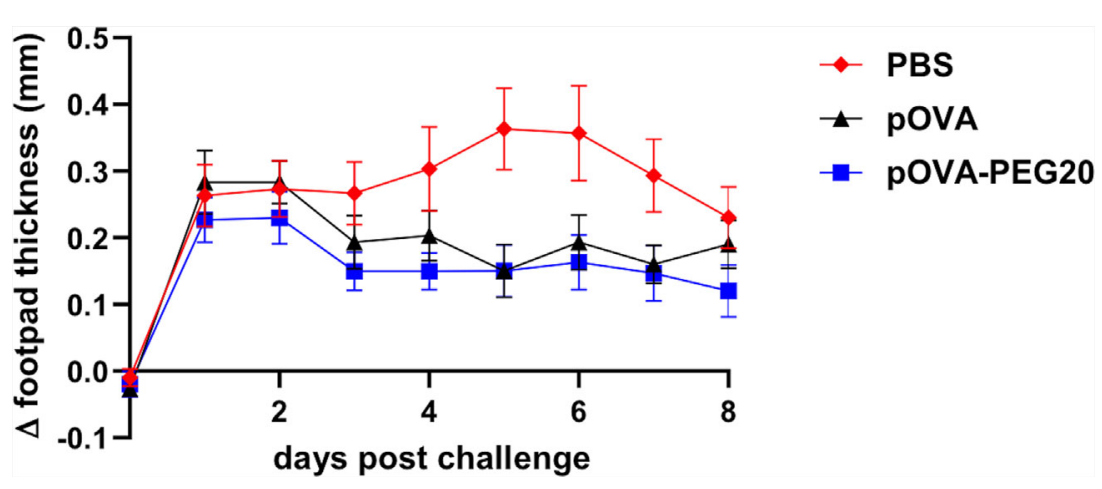

FIGURE 11 | Vaccination by either pOVA or pOVA-PEG20 confers partial tolerance in a Th1-driven DTH model. OVA-specific CD4 ${ }^{+}$cells were adoptively transferred into BALB/c mice, which were treated i.v. with PBS (control), $5 \mu \mathrm{g}$ of pOVA or equimolar amounts of pOVA-PEG20 $24 \mathrm{~h}$ later. On day 7 , in vitro generated OVAspecific Th1 cells were transferred into the recipients. After $24 \mathrm{~h}$, pOVA in IFA or the control, PBS/IFA, were injected into the left or right hind footpad, respectively. The difference in footpad thickness after challenge was monitored for eight consecutive days. Statistical testing was performed using the nonparametric Mann Whitney test and Holm-Bonferroni correction for multiple comparisons. Difference between pOVA-PEG20 and pOVA was significant with adjusted $p=0.03$. Data represent mean of $\Delta$ footpad thickness \pm SEM $(n=15)$.

peptide CG-323-339 poses the bulky PEG chain 8-10 amino acid residues away from the recognition motif. Nevertheless, we observed a strongly reduced stimulatory capacity of pOVAPEG conjugates compared to the native peptide in the in vitro assay. As to be expected, the tetramer conjugate was the most active compound in vitro, while, surprisingly, also the PEG40 was significantly more active than the PEG20 conjugate.

In vitro, peptides are predominantly directly loaded onto MHCII; this process could be impaired by the attached PEG moiety. Whether presentation of the conjugates requires intracellular or extracellular cleavage of the PEG-entity from the core peptide remains to be analyzed. Increasing the PEG size from 20 to $40 \mathrm{kDa}$ did not further reduce the biologic activity in vitro.

In contrast to the reduced in vitro stimulatory capacity of pOVA-PEG conjugates, a stronger proliferative response of
$\mathrm{T}$ cells was elicited in vivo. The magnitude of this effect was dependent on structure and size of the PEG molecule. Thus, impairment of presentation is compensated for by mechanisms increasing the biologic efficacy in vivo.

The stimulatory capacity of native peptides in vivo is restricted by enzymatic degradation and rapid renal clearance in the organism. This can be counteracted by PEGylation (44). We therefore hypothesized that PEGylation of peptide would lead to an extended bioavailability in vivo. To prove this hypothesis, the transgenic DO11.10 adoptive transfer model was modified in that conjugated or native peptide was given three days before transfer of reactive $\mathrm{T}$ cells, so that the retention time of the peptide within the body would play a critical role. Under these conditions, only marginal $\mathrm{T}$ cell activation was observed upon vaccination with non-modified pOVA and pOVA 


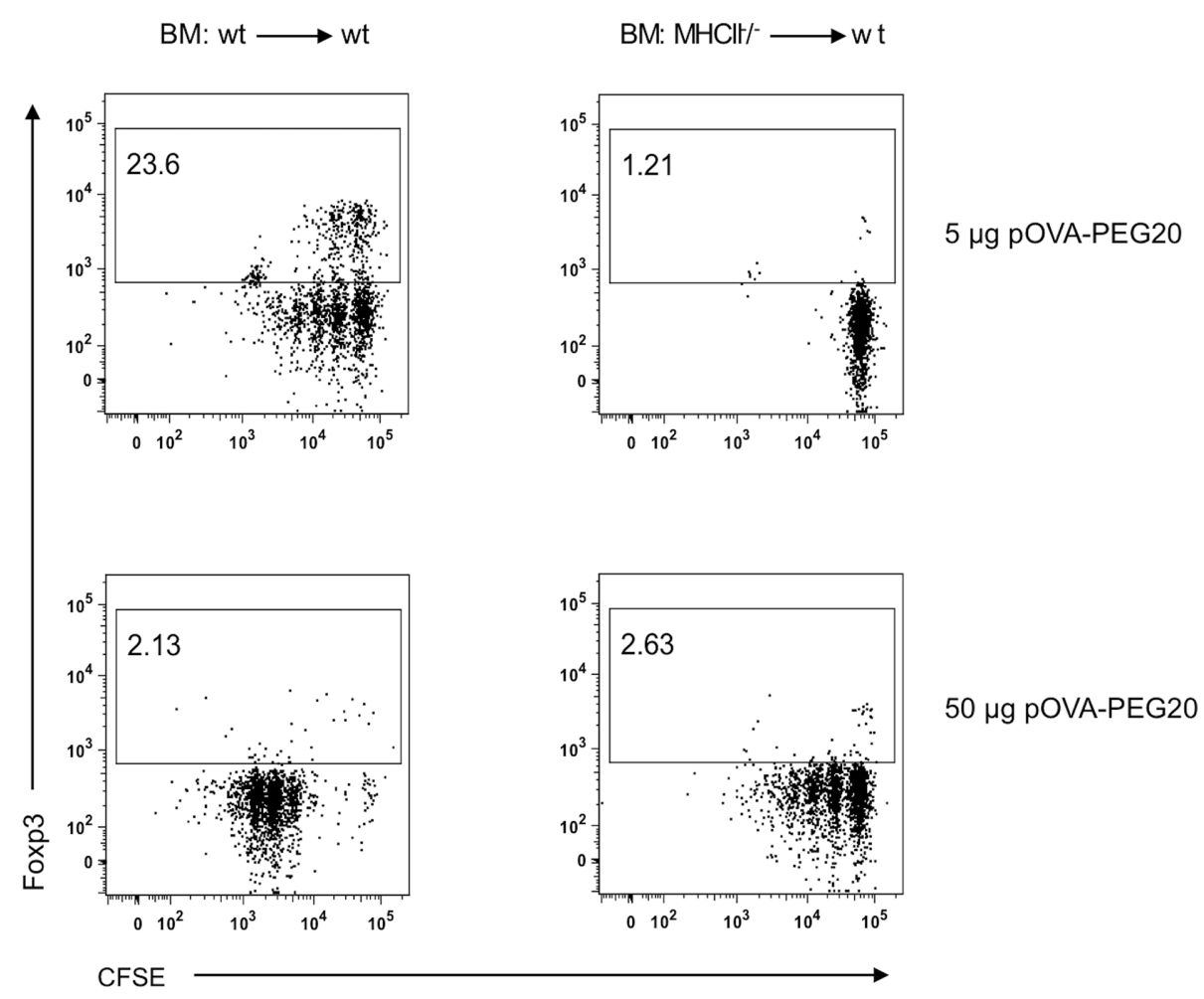

FIGURE 12 Non-hematopoietic APCs present pOVA-PEG20 and induce activation of OVA-specific T cells at high doses. OVA-specific CD4 ${ }^{+}$MHCII $/{ }^{-}$cells, isolated from OTIIXB6.PL $\left(\mathrm{CD} 90.1^{+}\right)$mice, were labeled with CFSE and transferred into controls or MHCll deficient BM (bone marrow) chimeras. After $24 \mathrm{~h}$, recipients received 5 or $50 \mu \mathrm{g}$ (based on peptide amount) of pOVA-PEG20. Proliferation as well as Foxp3 expression was assessed using flow cytometry on day 7. Splenocytes were gated on donor $\left(C D 90.1^{+}\right)$OVA-specific CD4 $4^{+} \mathrm{T}$ cells. Representative FACS dot plots from at least two independent experiments. wt: wild type.

conjugated to a small linear $12 \mathrm{kDa}$ PEG molecule, suggesting a complete systemic clearance within three days. In contrast, conjugation of pOVA with PEG20, PEG40, or as a tetramer significantly prolonged the bioavailability of the antigen. Modification of biomolecules with linear PEG molecules increases their hydrodynamic volume and thereby affects glomerular filtration (27). In agreement with our observations, Jorgenson and Moller previously showed that a minimum of 20 $\mathrm{kDa}$ is needed for a significant retardation of renal clearance (45).

Interestingly, administration of equimolar amounts (related to peptide) of pOVA-PEG-tetramer induced the strongest proliferation compared to other peptide-PEG-conjugates in spleen, although the molecular weight of the pOVA-PEGtetramer is in total approximately $11 \mathrm{kDa}$, i.e., below the minimum of $20 \mathrm{kDa}$. According to Veronese and colleagues, conjugation of branched PEGs achieves better proteolytic resistance than PEGylation with linear PEG of the similar net molecular weight (46). Alternatively, the tetravalent nature of pOVA-PEG tetramer could lead to an improved avidity in the MHC-peptide-TCR complex.

It should be noted that reported values for the serum half-life of PEGylated peptides, even of higher molecular weight, are rather in the range of $<1$ day (47). In the present study, PEGylation (except with PEG12) of the OVA-peptide allowed recognition by $\mathrm{T}$ cells beyond $72 \mathrm{~h}$. Beside the option that declined concentrations might still be sufficient for activation, improved uptake, tissue sequestration or intracellular storage of the conjugates can contribute to the extended bioavailability in vivo. Indeed, when FITC-conjugated pOVA-PEG20 was applied, DCs, macrophages, and, to a lesser extent, B cells became labeled, indicating uptake by these APC.

The key goal of inverse vaccination is the modulation of the immune system towards antigen-specific tolerance. We therefore investigated in this study whether mechanisms involved in tolerance such as Treg expansion/induction, anergy or depletion of antigen-specific cells are targeted by vaccination with PEGylated peptide.

Tregs can be peripherally induced by various protocols including oral $(48,49)$, intranasal $(50)$, or intravenous (51) antigen administration. We here demonstrate that the systemic administration of PEG20-conjugated pOVA at a dose of $5 \mu \mathrm{g}$ (based on peptide amount) results in a significantly elevated frequency of pOVA-TCR ${ }^{+}$Foxp $^{+}$Tregs compared to unconjugated pOVA. While pOVA-PEG40 and pOVA-PEGtetramer most effectively induced proliferation, Treg frequencies did not exceed those upon pOVA exposure. This supports the notion that size and structure of the PEG-scaffolds affects both quality and quantity of the immune response. This was also 
found in our previous study using a different synthetic scaffold, dendritic oligoglycerol (OG)- and polyglycerol (PG)nanoparticles loaded with OVA-peptide. These conjugates also induced Foxp $3^{+}$Tregs (20), but chemistry, size, and structure of the synthetic carrier played a critical role for their tolerogenic potential, same as found by $(18,19,22)$.

In accordance to previous studies using native peptide (51), high doses of antigen were less effective in inducing Tregs, while in our study doses below $5 \mu \mathrm{g}$ (not studied by these authors) were also less effective, resulting in a bell-shape dose-response curve. The superior effect of PEG20-conjugates was highly significant only at this dose, highlighting the importance of optimal dosing in tolerance induction.

In order to analyze whether the increased frequencies of Foxp ${ }^{+}$ Tregs are due to de novo induction or result from expansion of preexisting Tregs, $\mathrm{CD} 25^{+}$Tregs were depleted prior to adoptive transfer of OVA-specific $\mathrm{CD}^{+}$cells. Significant numbers of Foxp $3^{+}$Tregs were found upon vaccination with pOVA or pOVA-PEG20 in all organs analyzed, indicating de novo generation from naïve cells. We can exclude that this is due to small numbers of Tregs remaining in the Treg-depleted preparation, as a previous study on oral tolerization (49) demonstrated that the small percentage of Tregs remaining in Treg-depleted cells is not preferentially expanding. As frequencies of Foxp $3^{+}$cells induced were lower than for total CD $4^{+}$ cells, it can be concluded that both de novo induction and expansion of pre-existing Tregs might account for the total frequency of up to $30 \%$ Tregs in spleen upon vaccination with pOVA-PEG20.

Interestingly, in the present study de novo induction of Foxp $3^{+}$Tregs was most prominent in the liver-draining lymph node (livLN). Several studies have shown a pivotal role for the livLN in generation of suppressive CD25 $5^{+}$Tregs following oral antigen administration $(49,52)$ and provided evidence that the microenvironment of the liver is biased towards tolerogenic responses $(42,53,54)$. In particular, the liver sinusoidal endothelial cells (LSEC) have been shown to down-regulate $\mathrm{CD}^{+} \mathrm{T}$ cell responses $(34,53)$. Controversial findings are reported regarding the capacity of LSEC to induce Foxp $3^{+}$ Tregs: Carambia and colleagues observed a $\mathrm{TGF}_{\beta}$-dependent induction of $\mathrm{CD}^{+}{ }^{+} \mathrm{Foxp}^{+}$Tregs by LSECs and demonstrated that antigen-loaded nanoparticles targeting LSECs could efficiently prevent the onset or ameliorate established EAE, mediated by Treg induction $(55,56)$. In contrast, Kruse et al. observed that activation of $\mathrm{CD}^{+}$cells using ex vivo LSECs as APC or a $\mathrm{MHCII}^{-/-} \mathrm{BM}$ chimeric mouse model resulted in anergic and suppressive T cells which were Foxp $3^{-}$but able to suppress inflammation in autoimmune hepatitis (34).

We therefore studied here whether non-hematopoietic cells were involved in the activation of $\mathrm{CD}^{+} \mathrm{T}$ cells and conversion into Tregs following administration of pOVA-PEG20. In BM-chimeric mice lacking $\mathrm{MHCII}^{+}$hematopoietic APC, the standard dose of $5 \mu \mathrm{g}$ of peptide did not lead to a significant $\mathrm{T}$ cell response, while the tenfold dose induced proliferation. In accordance with (34), the T cells proliferating at high peptide dosis in the chimeric mice largely lacked Foxp3. We conclude that the non-hematopoietic cells including LSEC do not significantly contribute to the $\left(\right.$ Foxp $\left.3^{+}\right)$Treg-inducing capacity of pOVA-PEG conjugates.
Experiments analyzing the uptake of fluorescently labeled pOVA-PEG did not provide hints for a selective uptake by a certain subset of conventional APC. However, this does not exclude that a specific type of APC is crucial for the conversion of naïve $\mathrm{T}$ cells into Tregs.

Various studies have demonstrated that induction of Tregs as well as their function becomes impaired in the presence of inflammatory signals. $(51,57,58)$. In agreement with these findings, pOVA-PEG20-mediated induction/expansion of Foxp3+ Tregs was suppressed in presence of LPS. Furthermore, as previously reported (59), Th1 cells were largely resistant to conversion into Tregs, despite a minute increase in Foxp $3^{+}$cells. These features of tolerance induction let predict that therapeutic application of pegylated peptides will be feasible in a preventive setting, but for established disease, at most during remission phases or under combinatorial treatment strategies combining suppression of inflammation with induction of Tregs.

Beside dominant suppression mediated by Tregs, peripheral tolerance (3) also involves deletion of antigen-specific cells by activation-induced cell death (60) and anergy (4), e.g., failure of antigen-reactive cells to produce pro-inflammatory cytokines. The data of this study point to a partial deletion of antigenspecific effector cells upon injection of pOVA-PEG, as also found upon vaccination with multimerized $\mathrm{T}$ cell epitopes (61) and $\mathrm{T}$ cell epitopes linked to parasite-derived tandem repeats (17).

Inflammatory cytokines such as TNF are major players in pathogenicity and TNF is a major target for treatment, e.g., in rheumatoid arthritis (62). Loss of effector functions such as secretion of cytokines has proposed to play a significant role in peripheral tolerance $(4,59)$. We studied the impact of peptide vaccination on TNF production as a flagship of inflammatory cytokines. We found that administration of pOVA-PEG conjugates resulted in reduced frequencies of TNF-producing cells after restimulation with PMA/ionomycin. pOVA-PEG40 and pOVAPEG-tetramer yielded the greatest reduction of TNF-producing cells, correlating with an increased stimulatory capacity. To assess the combined impact on both induction/expansion of Tregs and reduction of TNF-producing cells, we calculated the Foxp3/TNF ratio upon vaccination. pOVA-PEG20 most efficiently shifted this ratio in favor to regulatory immunomodulation compared to native pOVA and other pOVA-PEG conjugates. A similar diminished TNF- and increased Treg response was found upon vaccination with peptide conjugated to a parasite-derived carrier module (17). It remains to be shown whether these inhibitory effects on effector/ inflammatory pathways are robust enough to achieve a successful therapy in ongoing autoimmune disease.

For application of tolerogenic vaccination strategies, safety is of outstanding importance. In established disease, antigenspecific effector/memory cells, such as polarized Th1 cells, might be present, even when not activated. Previous studies reported adverse effects after administration of soluble autoantigen peptides due to activation or reactivation of effector/memory cells $(10,11)$. It was therefore important to analyze whether PEG-conjugated peptides are advantageous over free peptides in this respect. In fact, pOVA-PEG20 did not lead to an exacerbation of the immune response in mice adoptively 
transferred with Th1 cells to mimic an established disease. In spite of significant proliferation induced by both pOVA and pOVA-PEG20, only the latter did not give rise to increased frequencies and numbers of IFN $\gamma$-producing Th1 cells. It appears that the PEGylated peptide is enforcing mechanisms leading to activation-induced cell death rather than productive activation of effector cells. The reasons for this favorable property have yet to be elucidated.

In conclusion, the present investigations in the OVA-model suggest that vaccination with PEG-conjugated peptides is significantly more effective in inducing antigen-specific Tregs and less prone to adverse activation effects on the effector side than vaccination with free peptide. In addition, vaccination with the conjugates was favorable with respect to shifting the ratio between effector cells and regulatory cells. Thus, conjugation of autoantigen- or allergen-derived immunodominant peptides to PEG might be promising to increase efficacy and safety of tolerogenic vaccines.

While in a DTH-model based on Th1 cell transfer before challenge we observed only a minor improvement of the tolerogenic potential already shown by the native peptide upon use of the PEGylated conjugate, we found, in a forthcoming study, that vaccination with PEGylated myelinderived peptide MOG is much more effective in preventing disease in a mouse EAE-model for human multiple sclerosis (35). Thus, the value of the concept has finally to be proven in relevant preclinical models.

Compared to nanoparticle-based scaffolds, PEGylation appears to be advantageous as production and quality control might be easier. However, it has to be mentioned that the existence of antibodies in humans against PEG (mostly resulting from widespread use of PEG in cosmetics etc.) raised some concern (63). While such antibodies appeared not to interfere e.g., in trials using PEGylated interferon, in other cases biokinetics of PEGylated bacterial enzymes were found to be negatively affected $(63,64)$. Whether this issue will be of relevance for the type of conjugates used in our study remains to be analyzed.

We here confirmed repeated findings that a tolerogenic response is inhibited under inflammatory conditions as simultaneous delivery of LPS suppressed Treg generation. Thus, the capacity of a given vaccine not only to induce an antigen-specific Treg induction/expansion, but to suppress simultaneously and efficiently the activation of existing memory/effector cells or to suppress non-specific inflammatory signals might be crucial.

To achieve a maximum of both Treg-inducing and antieffector and anti-inflammatory effects, different strategies can be considered:

a. Combination of Treg-inducing agents such as peptide-PEG conjugates with agents or treatments suppressing effector mechanisms. The anti CD3 therapy already being in clinical testing is such a candidate, as it appears to cause the deletion of effector/memory cells (65).

b. Combining the tolerogenic peptide vaccination with antiinflammatory or Treg-promoting agents by their encapsulation in antigen-loaded nanoparticles. For this approach promising results have recently been reported $(21,23,66)$.

c. Certain types of nanoparticles appear by itself to induce downregulation of inflammatory signaling pathways in accessory cells; this might explain their encouraging preclinical efficacy in models of autoimmune disease $(19,22,67)$.

In conclusion, the old dream of inducing tolerance as an exclusively specific therapy for autoimmune diseases might come a step nearer by these recent developments.

\section{DATA AVAILABILITY STATEMENT}

All datasets generated for this study are included in the article/ Supplementary Material.

\section{ETHICS STATEMENT}

The animal study was reviewed and approved by Landesamt für Gesundheit und Soziales (LAGeSo), Turmstr. 21, 10559 Berlin.

\section{AUTHOR CONTRIBUTIONS}

JP, MS, UH, RK, FL, and AH conceived and designed the experiments. BT and RK synthesized and analyzed reagents. JP, MS, and UL performed the experiments. JP, MS, and PD analyzed the data. JP and AH wrote and edited the manuscript. All authors contributed to the article and approved the submitted version.

\section{FUNDING}

This work was supported by the German Research Foundation (CRC 650 TP1), by the Federal Ministry of Education and Research (Innovative Therapies -01GU0722-) and the Federal Ministry for Economic Affairs and Energy (ZIM -KF 2441003SK1-).

\section{ACKNOWLEDGMENTS}

We would like to thank the labmanagers in the DRFZ for technical support, Werner Tegge (HZI, Braunschweig) for initial help with the synthesis of conjugates, Katrin Neumann, Christine Rudolph, and Nils Kruse for introduction into the MHCII knockout BM chimera-model, and Alex Scheffold, UKSH, Kiel, for critical reading.

\section{SUPPLEMENTARY MATERIAL}

The Supplementary Material for this article can be found online at: https://www.frontiersin.org/articles/10.3389/fimmu.2020.529035/ full\#supplementary-material 


\section{REFERENCES}

1. Dolgin E. The inverse of immunity. Nat Med (2010) 16(7):740-3. doi: $10.1038 / \mathrm{nm} 0710-740$

2. Steinman L. Inverse vaccination, the opposite of Jenner's concept, for therapy of autoimmunity. J Internal Med (2010) 267(5):441-51. doi: 10.1111/j.13652796.2010.02224.x

3. Arnold B. Levels of peripheral T cell tolerance. Transpl Immunol (2002) 10 (2-3):109-14. doi: 10.1016/s0966-3274(02)00056-4

4. Schwartz RH. T cell anergy. Annu Rev Immunol (2003) 21:305-34. doi: 10.1146/annurev.immunol.21.120601.141110

5. Kretschmer K, Apostolou I, Hawiger D, Khazaie K, Nussenzweig MC, von Boehmer $\mathrm{H}$. Inducing and expanding regulatory $\mathrm{T}$ cell populations by foreign antigen. Nat Immunol (2005) 12:1219-27. doi: 10.1038/ni1265

6. Miller SD, Turley DM, Podojil JR. Antigen-specific tolerance strategies for the prevention and treatment of autoimmune disease. Nat Rev Immunol (2007) 7 (9):665-77. doi: 10.1038/nri2153

7. Pearson RM, Casey LM, Hughes KR, Miller SD, Shea LD. In vivo reprogramming of immune cells: Technologies for induction of antigenspecific tolerance. Advanced Drug Deliv Rev (2017) 114:240-55. doi: 10.1016/ j.addr.2017.04.005

8. van Eden W. Vaccination against autoimmune diseases moves closer to the clinic. Hum Vaccines Immunotherapeut (2019) 16(2):228-32. doi: 10.1080/ 21645515.2019.1593085

9. Sakaguchi S, Yamaguchi T, Nomura T, Ono M. Regulatory T cells and immune tolerance. Cell (2008) 133(5):775-87. doi: 10.1016/j.cell.2008.05.009

10. Genain CP, Abel K, Belmar N, Villinger F, Rosenberg DP, Linington C, et al. Late complications of immune deviation therapy in a nonhuman primate. Science (1996) 274(5295):2054-7. doi: 10.1126/science.274.5295.2054

11. Smith CE, Eagar TN, Strominger JL, Miller SD. Differential induction of IgEmediated anaphylaxis after soluble vs. cell-bound tolerogenic peptide therapy of autoimmune encephalomyelitis. Proc Natl Acad Sci USA (2005) 102 (27):9595-600. doi: 10.1073/pnas.0504131102

12. Bielekova B, Goodwin B, Richert N, Cortese I, Kondo T, Afshar G, et al. Encephalitogenic potential of the myelin basic protein peptide (amino acids 83-99) in multiple sclerosis: results of a phase II clinical trial with an altered peptide ligand. Nat Med (2000) 6(10):1167-75. doi: 10.1038/80516

13. Kappos L, Comi G, Panitch H, Oger J, Antel J, Conlon P, et al. Induction of a non-encephalitogenic type $2 \mathrm{~T}$ helper-cell autoimmune response in multiple sclerosis after administration of an altered peptide ligand in a placebocontrolled, randomized phase II trial. The Altered Peptide Ligand in Relapsing MS Study Group. Nat Med (2000) 6(10):1176-82. doi: 10.1038/ 80525

14. Diao L, Meibohm B. Pharmacokinetics and pharmacokineticpharmacodynamic correlations of therapeutic peptides. Clin Pharmacokinet (2013) 52(10):855-68. doi: 10.1007/s40262-013-0079-0

15. Smith CE, Miller SD. Multi-peptide coupled-cell tolerance ameliorates ongoing relapsing EAE associated with multiple pathogenic autoreactivities. J Autoimmun (2006) 27(4):218-31. doi: 10.1016/j.jaut.2006.12.002

16. Zubizarreta I, Florez-Grau G, Vila G, Cabezon R, Espana C, Andorra M, et al. Immune tolerance in multiple sclerosis and neuromyelitis optica with peptideloaded tolerogenic dendritic cells in a phase 1b trial. Proc Natl Acad Sci USA (2019) 116(17):8463-70. doi: 10.1073/pnas.1820039116

17. Puentes F, Dickhaut K, Hofstatter M, Pfeil J, Lauer U, Hamann A, et al. Immune Modulation and Prevention of Autoimmune Disease by Repeated Sequences from Parasites Linked to Self Antigens. J Neuroimmune Pharmacol OffJ Soc NeuroImmune Pharmacol (2016) 11(4):749-62. doi: 10.1007/s11481016-9701-x

18. Keijzer C, Slutter B, van der Zee R, Jiskoot W, van Eden W, Broere F. PLGA, PLGA-TMC and TMC-TPP nanoparticles differentially modulate the outcome of nasal vaccination by inducing tolerance or enhancing humoral immunity. PLoS One (2011) 6(11):e26684. doi: 10.1371/journal.pone.0026684

19. Hunter Z, McCarthy DP, Yap WT, Harp CT, Getts DR, Shea LD, et al. A biodegradable nanoparticle platform for the induction of antigen-specific immune tolerance for treatment of autoimmune disease. ACS Nano (2014) 8 (3):2148-60. doi: 10.1021/nn405033r

20. Gupta S, Pfeil J, Kumar S, Poulsen C, Lauer U, Hamann A, et al. Tolerogenic modulation of the immune response by oligoglycerol- and polyglycerol-
Peptide conjugates. Bioconjugate Chem (2015) 26(4):669-79. doi: 10.1021/ bc500608f

21. Maldonado RA, LaMothe RA, Ferrari JD, Zhang AH, Rossi RJ, Kolte PN, et al. Polymeric synthetic nanoparticles for the induction of antigen-specific immunological tolerance. Proc Natl Acad Sci USA (2015) 112(2):E156-65. doi: $10.1073 /$ pnas. 1408686111

22. Pearson RM, Podojil JR, Shea LD, King NJC, Miller SD, Getts DR. Overcoming challenges in treating autoimmuntity: Development of tolerogenic immune-modifying nanoparticles. Nanomed Nanotechnol Biol Med (2019) 18:282-91. doi: 10.1016/j.nano.2018.10.001

23. Kishimoto TK, Maldonado RA. Nanoparticles for the Induction of AntigenSpecific Immunological Tolerance. Front Immunol (2018) 9:230. doi: 10.3389/ fimmu.2018.00230

24. Ben-Akiva E, Est Witte S, Meyer RA, Rhodes KR, Green JJ. Polymeric microand nanoparticles for immune modulation. Biomater Sci (2018) 7(1):14-30. doi: $10.1039 / \mathrm{c} 8 \mathrm{bm} 01285 \mathrm{~g}$

25. Feng X, Xu W, Li Z, Song W, Ding J, Chen X. Immunomodulatory Nanosystems. Adv Sci (Weinh) (2019) 6(17):1900101. doi: 10.1002/ advs.201900101

26. Milla P, Dosio F, Cattel L. PEGylation of proteins and liposomes: a powerful and flexible strategy to improve the drug delivery. Curr Drug Metab (2012) 13 (1):105-19. doi: 10.2174/138920012798356934

27. Kang JS, Deluca PP, Lee KC. Emerging PEGylated drugs. Expert Opin Emerg Drugs (2009) 14(2):363-80. doi: 10.1517/14728210902907847

28. Hussain Z, Khan S, Imran M, Sohail M, Shah SWA, de Matas M. PEGylation: a promising strategy to overcome challenges to cancer-targeted nanomedicines: a review of challenges to clinical transition and promising resolution. Drug Delivery Transl Res (2019) 9(3):721-34. doi: 10.1007/s13346019-00631-4

29. Greenwald RB, Choe YH, McGuire J, Conover CD. Effective drug delivery by PEGylated drug conjugates. Advanced Drug Deliv Rev (2003) 55(2):217-50. doi: $10.1016 / \mathrm{s} 0169-409 \times(02) 00180-1$

30. Fishburn CS. The pharmacology of PEGylation: balancing PD with PK to generate novel therapeutics. J Pharm Sci (2008) 97(10):4167-83. doi: 10.1002/ jps. 21278

31. Zheng JC, Lei N, He QC, Hu W, Jin JG, Meng Y, et al. PEGylation is effective in reducing immunogenicity, immunotoxicity, and hepatotoxicity of alphamomorcharin in vivo. Immunopharmacol Immunotoxicol (2012) 34(5):86673. doi: 10.3109/08923973.2012.666979

32. Mu Q, Hu T, Yu J. Molecular insight into the steric shielding effect of PEG on the conjugated staphylokinase: biochemical characterization and molecular dynamics simulation. PLoS One (2013) 8(7):e68559. doi: 10.1371/journal. pone.0068559

33. Kearney ER, Pape KA, Loh DY, Jenkins MK. Visualization of peptide-specific $\mathrm{T}$ cell immunity and peripheral tolerance induction in vivo. Immunity (1994) 1(4):327-39. doi: 10.1016/1074-7613(94)90084-1

34. Kruse N, Neumann K, Schrage A, Derkow K, Schott E, Erben U, et al. Priming of CD4+ $\mathrm{T}$ cells by liver sinusoidal endothelial cells induces CD25low forkhead box protein 3- regulatory $\mathrm{T}$ cells suppressing autoimmune hepatitis. Hepatology (2009) 50(6):1904-13. doi: 10.1002/hep.23191

35. Pfeil J, Simonetti M, Lauer U, von Thülen B, Durek P, Poulsen C, et al. Prevention of EAE by PEGylated Antigenic Peptides. bioRxiv (2020). doi: $10.1101 / 2020.09 .08 .280875$

36. Steinman RM, Hawiger D, Nussenzweig MC. Tolerogenic dendritic cells. Annu Rev Immunol (2003) 21:685-711. doi: 10.1146/annurev.immunol.21. 120601.141040

37. Thomson AW, Knolle PA. Antigen-presenting cell function in the tolerogenic liver environment. Nat Rev Immunol (2010) 10(11):753-66. doi: 10.1038/ nri2858

38. Kunkel D, Kirchhoff D, Nishikawa S, Radbruch A, Scheffold A. Visualization of peptide presentation following oral application of antigen in normal and Peyer's patches-deficient mice. Eur J Immunol (2003) 33(5):1292-301. doi: 10.1002/eji.200323383

39. Knolle PA, Schmitt E, Jin S, Germann T, Duchmann R, Hegenbarth S, et al Induction of cytokine production in naive $\mathrm{CD} 4(+) \mathrm{T}$ cells by antigenpresenting murine liver sinusoidal endothelial cells but failure to induce differentiation toward Th1 cells. Gastroenterology (1999) 116(6):1428-40. doi: 10.1016/S0016-5085(99)70508-1 
40. Campbell N, Yio XY, So LP, Li Y, Mayer L. The intestinal epithelial cell: processing and presentation of antigen to the mucosal immune system. Immunol Rev (1999) 172:315-24. doi: 10.1111/j.1600-065x.1999.tb01375.x

41. Westendorf AM, Bruder D, Hansen W, Buer J. Intestinal Epithelial Antigen Induces CD4+ T Cells with Regulatory Phenotype in a Transgenic Autoimmune Mouse Model. Ann N Y Acad Sci (2006) 1072(1):401-6. doi: 10.1196/annals. 1326.035

42. Crispe IN, Dao T, Klugewitz K, Mehal WZ, Metz DP. The liver as a site of Tcell apoptosis: graveyard, or killing field? Immunol Rev (2000) 174:47-62. doi: 10.1034/j.1600-0528.2002.017412.x

43. Robertson JM, Jensen PE, Evavold BD. DO11.10 and OT-II T cells recognize a C-terminal ovalbumin 323-339 epitope. J Immunol (2000) 164(9):4706-12. doi: 10.4049/jimmunol.164.9.4706

44. Sakane T, Pardridge WM. Carboxyl-directed pegylation of brain-derived neurotrophic factor markedly reduces systemic clearance with minimal loss of biologic activity. Pharm Res (1997) 14(8):1085-91. doi: 10.1023/ a: 1012117815460

45. Jorgensen KE, Moller JV. Use of flexible polymers as probes of glomerular pore size. Am J Physiol (1979) 236(2):F103-11. doi: 10.1152/ajprenal.1979.236.2.F103

46. Veronese FM, Caliceti P, Schiavon O. Branched and Linear Poly(Ethylene Glycol): Influence of the Polymer Structure on Enzymological, Pharmacokinetic, and Immunological Properties of Protein Conjugates. J Bioactive Compatible Polymers (1997) 12(3):196-207. doi: 10.1177/ 088391159701200303

47. Bailon P, Won CY. PEG-modified biopharmaceuticals. Expert Opin Drug Deliv (2009) 6(1):1-16. doi: 10.1517/17425240802650568

48. Zhang X, Izikson L, Liu L, Weiner HL. Activation of CD25+CD4+ regulatory T cells by oral antigen administration. J Immunol (2001) 167(8):4245-53. doi: 10.4049/jimmunol.167.8.4245

49. Siewert C, Lauer U, Cording S, Bopp T, Schmitt E, Hamann A, et al. Experiencedriven development: effector/memory-like alphaE+Foxp3+ regulatory $\mathrm{T}$ cells originate from both naive $\mathrm{T}$ cells and naturally occurring naive-like regulatory $\mathrm{T}$ cells. J Immunol (2008) 180(1):146-55. doi: 10.4049/jimmunol.180.1.146

50. Unger WW, Hauet-Broere F, Jansen W, van Berkel LA, Kraal G, Samsom JN. Early events in peripheral regulatory $\mathrm{T}$ cell induction via the nasal mucosa. J Immunol (2003) 171(9):4592-603. doi: 10.4049/jimmunol.171.9.4592

51. Thorstenson KM, Khoruts A. Generation of anergic and potentially immunoregulatory $\mathrm{CD} 25+\mathrm{CD} 4 \mathrm{~T}$ cells in vivo after induction of peripheral tolerance with intravenous or oral antigen. J Immunol (2001) 167(1):188-95. doi: 10.4049/jimmunol.167.1.188

52. Hultkrantz S, Ostman S, Telemo E. Induction of antigen-specific regulatory $\mathrm{T}$ cells in the liver-draining celiac lymph node following oral antigen administration. Immunology (2005) 116(3):362-72. doi: 10.1111/j.13652567.2005.02236.x

53. Knolle PA. Involvement of the liver in the induction of CD8 T cell tolerance towards oral antigen. Z Gastroenterol (2006) 44(1):51-6. doi: 10.1055/s-2005858988

54. Klugewitz K, Blumenthal-Barby F, Schrage A, Knolle PA, Hamann A, Crispe IN. Immunomodulatory effects of the liver: Deletion of activated CD4+ effector cells and suppression of IFN-g producing cells after intravenous protein immunization. $J$ Immunol (2002) 169:2407-13. doi: 10.4049/jimmunol.169.5.2407

55. Carambia A, Freund B, Schwinge D, Heine M, Laschtowitz A, Huber S, et al. TGF-beta-dependent induction of CD4(+)CD25(+)Foxp3(+) Tregs by liver sinusoidal endothelial cells. J Hepatol (2014) 61(3):594-9. doi: 10.1016/ j.jhep.2014.04.027
56. Carambia A, Freund B, Schwinge D, Bruns OT, Salmen SC, Ittrich H, et al. Nanoparticle-based autoantigen delivery to Treg-inducing liver sinusoidal endothelial cells enables control of autoimmunity in mice. J Hepatol (2015) 62 (6):1349-56. doi: 10.1016/j.jhep.2015.01.006

57. Belkaid Y, Oldenhove G. Tuning microenvironments: induction of regulatory T cells by dendritic cells. Immunity (2008) 29(3):362-71. doi: 10.1016/ j.immuni.2008.08.005

58. Caretto D, Katzman SD, Villarino AV, Gallo E, Abbas AK. Cutting edge: the Th1 response inhibits the generation of peripheral regulatory $\mathrm{T}$ cells. J Immunol (2010) 184(1):30-4. doi: 10.4049/jimmunol.0903412

59. Adler AJ. Peripheral Tolerization of Effector and Memory T Cells: Implications for Autoimmunity and Tumor-Immunity. Curr Immunol Rev (2005) 1(1):21-8. doi: 10.2174/1573395052952879

60. Janssen O, Sanzenbacher R, Kabelitz D. Regulation of activation-induced cell death of mature T-lymphocyte populations. Cell Tissue Res (2000) 301(1):8599. doi: 10.1007/s004419900155

61. Puentes F, Dickhaut K, Hofstatter M, Falk K, Rotzschke O. Active suppression induced by repetitive self-epitopes protects against EAE development. PLoS One (2013) 8(5):e64888. doi: 10.1371/journal.pone.0064888

62. Feldmann M. Development of anti-TNF therapy for rheumatoid arthritis. Nat Rev Immunol (2002) 2(5):364-71. doi: 10.1038/nri802

63. Zhang P, Sun F, Liu S, Jiang S. Anti-PEG antibodies in the clinic: Current issues and beyond PEGylation. J Control Release (2016) 244(Pt B):184-93. doi: 10.1016/j.jconrel.2016.06.040

64. Poppenborg SM, Wittmann J, Walther W, Brandenburg G, Krahmer R, Baumgart $\mathrm{J}$, et al. Impact of anti-PEG IgM antibodies on the pharmacokinetics of pegylated asparaginase preparations in mice. Eur $J$ Pharm Sci (2016) 91:122-30. doi: 10.1016/j.ejps.2016.06.007

65. You S, Chatenoud L. Revisiting the phenotypic and genetic profiling of anergic $\mathrm{T}$ cells mediating long-term transplant tolerance. Curr Opin Organ Transplant (2018) 23(1):83-9. doi: 10.1097/MOT.0000000000000494

66. LaMothe RA, Kolte PN, Vo T, Ferrari JD, Gelsinger TC, Wong J, et al. Tolerogenic Nanoparticles Induce Antigen-Specific Regulatory T Cells and Provide Therapeutic Efficacy and Transferrable Tolerance against Experimental Autoimmune Encephalomyelitis. Front Immunol (2018) 9:281. doi: 10.3389/fimmu.2018.00281

67. Kuo R, Saito E, Miller SD, Shea LD. Peptide-Conjugated Nanoparticles Reduce Positive Co-stimulatory Expression and T Cell Activity to Induce Tolerance. Mol Ther J Am Soc Gene Ther (2017) 25(7):1676-85. doi: 10.1016/ j.ymthe.2017.03.032

Conflict of Interest: The authors BT, RK, and FL were employed by Celares GmbH, a company offering contract development services to the pharmaceutical industry.

The remaining authors declare that the research was conducted in the absence of any commercial or financial relationships that could be construed as a potential conflict of interest.

Copyright $\odot 2020$ Pfeil, Simonetti, Lauer, Volkmer, von Thülen, Durek, Krähmer, Leenders, Hamann and Hoffmann. This is an open-access article distributed under the terms of the Creative Commons Attribution License (CC BY). The use, distribution or reproduction in other forums is permitted, provided the original author(s) and the copyright owner(s) are credited and that the original publication in this journal is cited, in accordance with accepted academic practice. No use, distribution or reproduction is permitted which does not comply with these terms. 